\title{
Improving Access to Savings through Mobile Money: Experimental Evidence from African Smallholder Farmers*
}

\author{
Catia Batista ${ }^{\dagger}$ and Pedro C. Vicente
}

January 2020

\begin{abstract}
Investment in improved agricultural inputs is infrequent for smallholder farmers in Africa. One barrier may be limited access to formal savings. This is the first study to use a randomized controlled trial to evaluate the impact of using mobile money as a tool to promote agricultural investment. For this purpose, we designed and conducted a field experiment with a sample of smallholder farmers in rural Mozambique. This sample included a set of primary farmers and their closest farming friends. We work with two cross-randomized interventions. The first treatment gave access to a remunerated mobile savings account. The second treatment targeted closest farming friends and gave them access to the exact same interventions as their primary farmer counterparts. We find that the remunerated mobile savings account raised mobile savings, but only while interest was being paid. It also increased agricultural investment in fertilizer, although there was no change in investment in other complementary inputs that were not directly targeted by the intervention, unlike fertilizer. These results suggest that fertilizer salience in the remunerated savings treatment may have been important to focus farmers' (limited) attention on saving some of their harvest proceeds, rather than farmers being financially constrained by a lack of alternative ways to save. Our results also suggest that the network intervention where farming friends had access to non-remunerated mobile money accounts decreased incentives to save and invest in agricultural inputs, likely due to network freeriding because of lower transfer costs within the network. Overall this research shows that tailored mobile money products can be used effectively to improve modern agricultural technology adoption in countries with very low agricultural productivity like Mozambique.
\end{abstract}

JEL Codes: D14, D85, Q12, Q14.

Keywords: Mobile Money; Social Networks; Savings and Agricultural Investment; Randomized Field Experiment; Mozambique; Africa.

\footnotetext{
* We are indebted to Dean Yang, who made important contributions to this project. We are grateful to Luke Crowley, Guilherme Rodrigues, Diogo Mendes, and especially to Matilde Grácio, for excellent field coordination. We thank seminar and conference participants at CERDI at the University of Auvergne, CSAE at Oxford University, IGC at the LSE, IPA at Northwestern University, Sustainability and Development Conference at Michigan University, and NOVAFRICA at Lisbon's Nova SBE for useful comments. We are particularly grateful to Carteira Móvel, Mcel, and the International Growth Centre for fruitful collaboration in Mozambique. Nadean Szafman and his team, and Mindy Hernandez offered important inputs to this project for which we are most thankful. Finally, we would like to extend an appreciative word to the group of enumerators with whom we worked. IRB approval was secured from Innovations for Poverty Action. We wish to acknowledge financial support from ATAI at MIT, and USAID. All errors are our responsibility.

${ }^{\dagger}$ Universidade Nova de Lisboa, NOVAFRICA, and IZA. Email: catia.batista@novasbe.pt.

* Universidade Nova de Lisboa, NOVAFRICA, and BREAD. Email: pedro.vicente @ novasbe.pt.
} 


\section{Introduction}

African farmers have a hard time saving. First, they are typically poverty-ridden smallholder farmers. ${ }^{1}$ Second, they are usually unbanked. ${ }^{2}$ Without access to formal financial products, namely those entailing some degree of commitment, they are easy prey to the pressures of their families and neighbors, and to their own temptations. ${ }^{3}$ In this context, saving may be crucial to break the cycle of low investment and low agricultural productivity that is typical of many rural settings in Africa. Improved agricultural technologies, with the potential to have clear impacts on productivity, have yet to be widely adopted in the African continent, where fertilizer use is the lowest in the world. ${ }^{4}$ Enabling access to formal savings may be part of the solution to this important development challenge.

At the same time, the so-called mobile money revolution is making its way across Africa. The first mobile money service, M-PESA, was launched in 2007 in Kenya and was quickly adopted by a majority of the adult population of the country. ${ }^{4}$ Other countries followed, even if at lower rates of adoption. Based on a network of agents, standard mobile money platforms enable users to save money in their accounts and to send money to other people. All they need is a mobile phone with network coverage. Mobile money has an enormous potential to expand access to formal financial products. However, the way to tailor mobile money services to help farmers to save is not obvious. Indeed, it is possible that mobile money by itself de-incentivizes savings by facilitating transfers to other people, making them more vulnerable to social pressure within their social networks. Clear incentives to save, starting with interest-bearing savings accounts, are yet to be introduced in most mobile money platforms, often because regulators have limited knowledge about their potential impact.

In this paper, we report on a field experiment we designed and conducted in rural Mozambique in 2013 with a sample of smallholder farmers cultivating maize in non-irrigated plots. Mobile

\footnotetext{
${ }^{1}$ According to the Food and Agriculture Organization (FAO) of the United Nations, 95 percent of farms are smaller than 5 hectares and make up the majority of farmland in Sub-Saharan Africa. http://www.fao.org/family-farming/regions/africa/en/ [Last accessed on September 28, 2019.]

2 The 2017 World Bank Global Findex report finds that roughly $70 \%$ of adult sub-Saharan Africans in rural areas do not have a bank account, up from $81 \%$ in 2011.

${ }^{3}$ Ashraf et al. (2006), Dupas and Robinson (2013a) and Goldberg (2017) provide support to this claim. ${ }^{4}$ The FAO Statistical Yearbook reports that in 2011 the world average for nitrogen fertilizer use was 73.3 $\mathrm{Kg} / \mathrm{ha}$ and the sub-Saharan African average was $13.3 \mathrm{Kg} / \mathrm{ha}$.

${ }^{4}$ See Jack and Suri (2011) and Mbiti and Weil (2011) for a detailed description of the introduction of MPESA in Kenya.
} 
money had recently been launched in urban areas of Mozambique, but not in the rural areas where we conducted our study: mobile money was newly introduced for the purpose of this project in the rural areas included in our sample. Our experimental design aims at investigating the role of offering remunerated mobile money savings accounts to farmers on their financial behavior and investment. We assess changes in saving behavior, investment in improved inputs, with an emphasis on fertilizer, and household expenditures. We also examine the role of exogenously introducing network adoption (relative to individual adoption) of mobile money on the same outcomes, and evaluate interaction effects between the two interventions.

We adopted a $2 \times 2$ experimental design based on two cross-randomized treatments: the "savings treatment" that provided access to a remunerated savings account through mobile money; and the "network treatment" which provided symmetric treatment to the two closest farming friends of the primary experimental subjects (i.e. gave the secondary farmers access to the exact same interventions as their primary farmer counterparts). For this purpose, we study a sample of smallholder farmers, our experimental subjects, which includes a group of 196 primary farmers and a group of 392 secondary experimental subjects, which included the two closest farming friends of each primary farmer. Note that all primary subjects in our sample, regardless of their treatment status, received a free mobile phone, information and training about using mobile money services - namely all primary farmers in our sample were assisted in opening a mobile money account, received some seed money and performed trial mobile money transactions. All primary farmers also received an information module on the importance of using urea fertilizer and specific instructions on how to use it. All farmers were also given the opportunity to sell maize and to purchase urea fertilizer. These same modules on mobile money and fertilizer usage were also provided to all secondary experimental subjects (the two closest farming friends of each primary subject) when treated symmetrically to their primary counterparts under the "network treatment": these secondary subjects were given not only a mobile phone and mobile money account, but also an introduction to mobile money services (including trial money and transactions) and information on fertilizer use and its importance.

Our measurement of the outcomes of the randomized interventions is based on: (i) administrative data for mobile money transactions between July 2013 and June 2015, made available by the mobile money operator that partnered with us in this study; (ii) survey data on savings behavior, fertilizer use, household expenditures, and transfers sent and received. Since we conducted both baseline and follow-up surveys, we estimate Ancova regressions for most of our outcomes of interest. 
We find clear positive effects of the remunerated savings treatment on savings in the mobile money platform, significant during the first year when interest payments were made. The role of transfers received by farmers in their mobile money accounts, likely from outside of the village network, seems to be particularly important in mediating this effect. In terms of agricultural inputs, the probability of using fertilizer increased very significantly between 34 and 36 percentage points. We find however that farmers in the savings treatment group did not increase investment in other technologies that complement fertilizer usage (such as use of improved seeds, hiring of farm workers and use of irrigation pumps), and which, unlike fertilizer, were not directly mentioned in any of the interventions the farmers were exposed to. These results suggest the importance of fertilizer salience in our savings treatment: since the interest payment in the savings treatment was paid in fertilizer, offered right after harvest, the time of the year when farmers have most financial resources available, we argue that this fertilizer bonus may have acted as a "reminder" and focused farmers' (limited) attention to saving some of the recent harvest proceeds to invest in fertilizer. This evidence, together with the fact that mobile savings only increased while interest was being paid on its balance, leads us to believe that more than being financially constrained by a lack of alternative ways to save, the farmers we worked with may generally have limited attention to investment in fertilizer and other modern agricultural techniques.

The second dimension of our experiment, the "network treatment", measured the impact of close farming friends being given access to the same opportunities offered to primary experimental subjects. For primary farmers in the network treatment group but not under the (crossrandomized) savings treatment, this meant that secondary farmers were given a free phone, a mobile money account, trial mobile money transactions and an information module about fertilizer use. For primary farmers under both the network and the savings treatment, the network treatment additionally provided interest on the mobile savings of secondary farmers. The effects of this network intervention on savings and investment are less strong and clear to interpret than those of the incentivized savings intervention. The network treatment decreased savings (especially for those farmers who did not receive any savings incentive) and may also have reduced fertilizer usage (although this effect cannot be precisely estimated when accounting for multiple hypotheses testing). No statistically significant effect on expenditures could be detected.

These results are consistent with the network treatment giving rise to network free-riding effects, where treated farmers save less because the network access to mobile money reduced the transactions costs of transfers thereby discouraging saving behavior. Alternative hypotheses such 
as the network treatment shielding farmers from social pressure, or promoting network information/imitation do not gather empirical support from our experiment.

Our work contributes to the growing experimental literature on financial and behavioral interventions to promote agricultural productivity. ${ }^{5}$ In particular, this is the first piece of research to use a randomized controlled trial to evaluate the impact of using mobile money as a tool to promote agricultural investment.

In an influential study, Duflo et al. (2011) showed how small discounts for fertilizer purchases just after harvest time could significantly increase agricultural investment in fertilizer, particularly among unsophisticated present-biased farmers who had enough liquidity right after harvest, but no longer at the time of fertilizer use. The intervention we implemented in our work is similar to the one presented by Duflo et al. (2011) in the sense that it also nudges farmers into early (self-) commitment of resources for agricultural investment, thereby protecting their resources from spending due, for example, to lack of self-control or social pressure to share resources. ${ }^{6}$ In this sense, our work can be understood as proposing mobile savings as an alternative tool that can be tailored to promote agricultural investment.

Using financial tools with various degrees of commitment to counteract behavioral biases and social pressures to spend has been documented to increase savings and investment in different settings, most notably by Ashraf et al. (2006). Other work, namely by Dupas and Robinson (2013a) and, more recently, Dupas et al. (2018), focuses on the role of simply making available a safe place to save. The results of these studies vary across settings: while in Kenya a safe place to keep money was enough to substantially increase savings, in Malawi, Uganda and Chile the safe savings intervention only had limited effects on a subsample of experimental subjects. Although our intervention does not include any hard commitment device, it goes beyond providing a safe

place to save, and it also adds incentives to save that are explicitly framed as for investment in fertilizer. Our work cannot therefore provide evidence that just providing a safe place to save (the mobile money account) contributes to agricultural investment - indeed in a randomized experiment

\footnotetext{
${ }^{5}$ A recent literature review is provided by de Janvry et al. (2017).

${ }^{6}$ Social pressure to share resources within networks is a powerful force at work in many developing countries. Indeed, a study of credit cooperatives in Cameroon by Baland et al. (2011) shows members bearing significant costs to protect their savings from friends and relatives. Consistently, Jakiela and Ozier (2016) find that, in the context of a lab experiment in Kenya, women reduce their income in order to keep it hidden. Goldberg (2017) finds clear effects of redistributive pressure on the timing of expenditures in Malawi.
} 
in a similar rural context in Mozambique, Batista and Vicente (2018) find that the availability of mobile money account (explicitly labelled as a safe place to save in their dissemination effort) did not increase savings or agricultural investment. In this context, we interpret the positive savings and agricultural investment effects of offering a remunerated mobile savings account as a result of it being explicitly tailored for investment in fertilizer use drawing farmers' limited attention (as in Karlan et al., 2016) and offered right after harvest when farmers were less financially constrained (as in Duflo et al., 2011).

Brune et al. (2016) explore an experimental design in an agricultural setting in Malawi giving access to direct deposits of crop earnings to a commitment savings account, also finding increased savings and agricultural input usage. Similar to our work, this is another alternative way to nudge farmers into saving and agricultural modernization. Specifically in Mozambique, recent contributions have tested the impact of input subsidies and saving incentives (Carter et al., 2013). These authors find that farmers had low use of fertilizer and improved seeds coupons likely because of financial or informational constraints - a result consistent with our findings.

Note that our experimental design does not explicitly examine the role of other factors, such as information and its network diffusion, which have been shown to play an important role in agricultural technology adoption. ${ }^{7}$ In order to focus on the role of offering incentivized mobile savings accounts to individuals and their networks, we exclude these considerations from our experimental evaluation by providing all primary farmers, regardless of their treatment status, with an information module on best practices in the use of fertilizer.

A different branch of literature is related to the expansion of mobile money use in Africa. The recent literature has focused mostly on the Kenyan success story of M-PESA, and its risk sharing consequences. ${ }^{8}$ Batista and Vicente (2018) show that the randomized introduction of mobile

money in rural areas of Mozambique decreased the transaction costs of migrant remittances so that these not only improved insurance to shocks, but also prompted increased migration out of rural

\footnotetext{
${ }^{7}$ For example, Conley and Udry (2010) showed how information transmission between farmers was particularly important for investment especially by inexperienced farmers who looked mostly at the experience of more seasoned farmers facing similar circumstances. More recently, Beaman et al. (2015), and Ben Yishay and Mobarak (2018) have further detailed how farmer networks and network theory may be used to promote agricultural investment in a policy relevant manner.

${ }^{8}$ Jack et al. (2013) and Jack and Suri (2014) show that the consumption of households with access to MPESA is not hurt by idiosyncratic shocks, which implies that decreased transaction costs for transfers
} 
areas and less agricultural investment. Savings were not significantly changed due to the availability of mobile money. Similarly, De Mel et al. (2018) conducted a randomized impact evaluation of an intervention offering different levels of reduced fees charged to make a mobile deposit in Sri Lanka. Their results show that adoption was limited and concentrated on women and those living far from commercial banks, and that there were no increases in household savings or other welfare outcomes. Our paper suggests that mobile money can be tailored to counteract these negative results by incentivizing savings in a way that increases the salience and relevance of investing in a productive technology, such as agricultural fertilizer.

Most related to our work, several contributions show how mobile money can be tailored into promoting savings and productive investment. Jack and Habyarimana (2018) examine the impact of randomizing access to a mobile money savings account in Kenya as a way to successfully increase savings and access to high school. Batista et al. (2019) also facilitate access to a mobile money savings account as a tool to promote microenterprise development in Mozambique. In the same line, our paper tests the impact of offering remunerated mobile money savings accounts to individual farmers and their networks while taking into account the specificities of the timing constraints and behavioral biases associated with agricultural investment.

More generally, other work has described the potential of mobile money as a tool to promote economic development in different areas. The more recent paper by Jack and Suri (2016) documents positive effects of mobile money on savings in Kenya, along with impacts on occupational choices of women. Their overall poverty-reduction result is in line with Aker et al. (2016), who describe the positive poverty-reduction impact of a cash transfer program implemented using mobile money in Niger after a natural disaster. In a different context, Blumenstock et al. (2018) show how mobile salary payments can increase savings due to default enrollment in the program, even beyond its duration - highlighting the importance of behavioral constraints to saving and how these can be used to incentivize mobile savings, similar to the intervention we evaluate.

promote risk sharing. This evidence is confirmed by Riley (2018), who analyzes a panel of households in Tanzania, and by the experimental impact evaluation of the introduction of mobile money in rural areas of Mozambique by Batista and Vicente (2018). The paper is organized as follows. In section 2 we present the context of our field experiment. In section 3 we fully develop the experimental design, with treatments, hypotheses, sampling and assignment to treatment, measurement, and estimation strategy. The following section provides the econometric results, including balance tests, treatment effects on use of mobile money, savings, 
agricultural inputs use, expenditures, and transfers from/to closest farming friends. We conclude in section 5 .

\section{Country context}

Mozambique, a country with 25.8 million inhabitants, is one of the poorest countries in the world with GDP per capita of 1105 USD (current, PPP) in 2013 - it ranks 175 in 181 countries in terms of GDP per capita. Despite substantial natural resource discoveries and exploration in recent years, it is still a country with clear dependence on official aid assistance, which accounts for 57 percent of central government expenses. Agriculture is considered the key sector in Mozambique for those interested in pro-poor economic policies, as it accounts for 81 percent of the employment in the country. Despite this impressive figure, the contribution of the agricultural sector for the value added of the country is only 29 percent. $^{9}$

Cereal agricultural productivity for 2011 in Mozambique was 10.4 thousand hectograms per hectare, well below the world average, 36.6, and even below the African average, 14.4. ${ }^{10}$ Two factors may help explaining this particularly low agricultural productivity. First, smallholder farmers constitute the vast majority of farmers in the country: data from the National Agricultural Survey (TIA) in 2008 indicate that only 0.58 percent of Mozambican farmers cultivate more than 10 hectares of land. Second, investment in improved inputs is very limited: for example, the FAO Statistical Yearbook reports that in 2011 the Mozambican average for nitrogen fertilizer use was 6.4 kilograms per hectare, which is well below both the world average $(73.3 \mathrm{Kg} / \mathrm{ha})$ and the African average $(13.3 \mathrm{Kg} / \mathrm{ha})$. In an extremely poor setting like rural Mozambique, it is likely that smallholder farmers have difficulties in saving resources, from harvest to planting, for investing in improved agricultural inputs like fertilizers. ${ }^{11}$

Access to financial services is very limited in Mozambique, specifically in rural areas. In 2013, only 24 bank accounts existed for each 100 Mozambican adults, and the number of bank branches per

\footnotetext{
${ }^{9}$ World Development Indicators, 2015, latest available years.

${ }^{10}$ FAO Statistical Yearbook, 2014.

${ }^{11}$ Cunguara and Darnhofer (2011) show that improved agricultural technologies are associated with higher household incomes for smallholder farmers in Mozambique, when these farmers have secured access to markets. In addition to fertilizers, Batista, Bryan and Karlan (2018) report that farm productivity of smallholder farmers in northern Mozambique is especially improved when they adopt techniques such as
} 
100,000 adults was 3.9. Both figures were below their corresponding African averages, which were 55 and 7.7 , respectively. ${ }^{12}$ Saving methods for the rural population are often limited to keeping money at home, keeping money informally with someone, and to participating in savings groups. ${ }^{13}$

The introduction of mobile money in 2011 created expectations that the level of financial inclusion could improve quickly in the country. Mozambique had around five million subscribers of mobile phone services in a competitive market, and geographical coverage included 80 percent of the population. ${ }^{14}$

mKesh became the first mobile money service operating in Mozambique: it was offered by Carteira Móvel, a financial institution created by Mcel, the main mobile telecommunication operator in the country. In an initial effort to recruit mKesh agents, Carteira Móvel recruited 1000 agents in just a few months after September 2011. However, these agents were based mainly in urban locations, particularly in Maputo city. During the first years most of mKesh's expansion efforts, specifically in terms of agent coverage, were concentrated in urban locations. ${ }^{16}$ Agent coverage has been very slow in rural areas both because of underdeveloped telecommunications infrastructure. Geographic expansion of agent networks is also limited by traditional brick-andmortar banking infrastructure, which is necessary for liquidity management, as agents still need to be situated near banks or "superagents" with agent-to-agent transfer capabilities to balance their floats.

pit planting and using hybrid seeds - relative to other agricultural practices, such as mulching or using OPV seeds.

Even though the Mozambican Central Bank does not allow mobile money operators to offer saving products of their own (i.e., earning interest paid by the mobile money operator), mobile money can still be seen as an attractive saving method, namely for farmers who live far from bank branches.

\footnotetext{
12 IMF, Financial Access Survey, 2015.

${ }^{13}$ Batista and Vicente (2018) report for a large sample of rural Mozambican households surveyed in 2012 the following statistics: 63 percent save money at home, 30 percent save money informally with someone, and 21 percent participate in a savings group. Only 21 percent report any money saved in a bank account. Numbers are similar for an urban sample of market vendors also in Mozambique (Batista, Sequeira and Vicente, 2019).

${ }^{14}$ Computed from data made available by Mcel and Vodacom, the two existing Mozambican mobile telecommunication operators in 2011. In 2012 a third operator entered the mobile phone market (Movitel). 16 M-PESA, operated through a financial institution controlled by Vodacom, entered the mobile money market in late 2013, after our experiment had started, and was only serving urban areas at that point.
} 


\section{Experimental design}

\subsection{Design}

Our experiment encompasses two interventions, cross-randomized in a $2 \times 2$ design, submitted at the individual level. The pool of primary experimental subjects includes 196 farmers at the baseline. All primary experimental subjects, regardless of their treatment status, were given two modules after the baseline: one on mobile money, and one on the use of fertilizer.

The first randomized intervention is an incentivized savings treatment, which allows individuals to receive a bonus (or, more precisely, interest) depending on the average balance they held on their mobile money account over a pre-specified period. The second intervention is a network treatment that gives the two closest farming friends of primary subjects the exact same interventions that their primary counterparts received. Specifically, all the (network-treated) farming friends were given the information modules on mobile money and fertilizer use. In addition, the interaction of the savings and network interventions also provided primary farmers' connections with access to the mobile money savings bonus.

The experimental design offered by our structure of treatments is depicted in Figure 1. Farmers subject to the incentivized savings intervention ("the savings treatment") are denoted by $S$, whereas control farmers not subject to the same intervention are represented by $C$. $N$ stands for the group of farmers subject to the network intervention ("the network treatment"), and I corresponds to the group of individual farmers not subject to this network intervention. In light of this notation, we can define four treatment groups:

1. the $C I$ group ( $C$ standing for control, i.e., no savings treatment; and $I$ for individual, i.e., no network treatment) is not subject to neither the savings, nor the network treatments: that all primary farmers in this group received not only information about mobile money and fertilizer usage, but also a free mobile phone, a mobile money account, seed mobile balance and trial mobile money transactions;

2. the SI group ( $S$ standing for savings treatment; and $I$ for individual, i.e., no network treatment) benefits from the savings treatment, but not from the network treatment: the primary farmers in this group received the exact same mobile money and fertilizer modules 
as those in the CI group, but are additionally paid a bonus (interest) on their mobile money balances;

3. the $C N$ group ( $C$ standing for control, i.e., no savings treatment; and $N$ for network treatment) is exposed to the network treatment, but not to the savings treatment: all farmers in this group (including primary subjects and their two selected friends) received not only information about mobile money and fertilizer usage, but also a free mobile phone, a mobile money account, seed mobile balance and trial mobile money transactions;

4. the $S N$ group ( $S$ standing for savings treatment; and $N$ for network treatment) corresponds to the interaction of the two treatments: all primary and secondary farmers in this group benefit from the mobile money and fertilizer modules offered to all other groups, and also are paid interest on their mobile savings balance.

<Figure 1 near here>

\subsection{Implementation}

The information module on mobile money was a general introduction to mKesh, the only mobile money service being offered in Mozambique at the time of the experiment. Even though there was clear familiarity with mobile phone communication at the baseline, mobile money services were not previously available in the experimental locations, hence the need for this module to be provided to everyone in our sample.

This information module on mobile money started by offering a basic mobile phone (worth 750 Meticais, close to USD 30 at the time, in an Mcel shop), and a leaflet explaining how to use mKesh and giving an overview of all possible services on offer. This leaflet is reproduced in Figure 2. Verbally, enumerators focused on explaining the meaning of saving, what a bank is, and some details about mKesh (ability to save using the service, safety based on a PIN, no need to go to a bank branch). After this verbal introduction, enumerators registered each individual on mKesh using the self-registration feature of the service, and gave 55 Meticais (close to USD 2) for cash-in (deposit) in their new mKesh account at the local mKesh agent. In the process of the cash-in operation, enumerators introduced the local mKesh agents to the experimental subjects. After the cash-in operation, enumerators assisted each individual to check his/her mKesh balance. 
Enumerators also explained how to cash-out (withdraw) the money from mKesh (making sure individuals understood that they had to pay a fee of 5 Meticais for that operation).

\section{$<$ Figure 2 near here>}

The information module on fertilizer use was based on a leaflet - reproduced in Figure 3 - which was delivered by enumerators and explained verbally. It focused on maize production and its main message was 'Using fertilizer is good! This year take good care of your machamba [agricultural plot]. Increase your production by increasing your soil fertility'. Details about fertilizer use were explained on one side of the leaflet: they included information on what farmers already do well (preparing the soil, placing seeds after first rains, using organic fertilizer, removing unwanted plants from plot during maize growth), and added information on how to apply urea as inorganic fertilizer two to three weeks after germination. These details were verbally discussed at length with experimental subjects. At the end of the module on fertilizer use, farmers were given information on the possibility of selling their maize to a local buyer (Desenvolvimento e Comercialização Agrícola - DECA). Note that our field team was available to mediate these sales, i.e., they were available to help farmers sell their maize from the recent harvest (July 2013) to DECA. Importantly, the proceeds of this sale could be paid to their mKesh account should the farmer so choose. Our team was also available to mediate the purchase of fertilizer for the planting season starting in November 2013. These resources were available to all farmers during team visits performed before the planting season.

\section{$<$ Figure 3 near here>}

The savings treatment was based on offering 20 percent interest on the average mKesh balance held by an individual over the period from the end of the research team visits before planting season to just before the follow-up survey in January/February 2014 (when urea fertilizer should be applied). This bonus was paid in urea fertilizer. The leaflet that was distributed announcing this treatment scheme is shown in Figure 4. Even though experimental subjects could cash-out the money on their mobile money account, this intervention provided a strong incentive to keep a high balance for as much time as possible until the end of the interest-paying period. Interest rates paid by banks in Mozambique approached but did not reach 10 percent on a full year in 2013 (as given by the reference rate of the Bank of Mozambique), and banking services were not available in these rural areas. In this sense, the savings treatment can be understood as a strong incentive to save. 
$<$ Figure 4 near here >

The network treatment gave the two closest farming friends of each treated primary experimental subject the modules on mobile money and fertilizer use. In addition to these modules, when interacted with the savings treatment, the network treatment also enabled access of the two closest friends to a bonus (interest) paid on their average mKesh balances.

Closest farming friends (secondary experimental subjects) were chosen using information collected during the farmer pre-project survey that took place before the baseline survey. Closest farming friends were defined as:

(i) connections residing in the same community that farm non-irrigated plots;

(ii) connections that farm non-irrigated plots in the same community as a farmer from whom that individual had a loan granted; and

(iii) connections that farm non-irrigated plots in the same community as a farmer to whom that individual granted a loan.

The selected closest friends could not be in the list of primary experimental subjects. When more than two farming friends were mentioned across the referred questions, priority was given to connections that were mentioned in more than one of the (i) to (iii) lists for a given individual. The possibility of overlaps of closest farming friends between different primary subjects was ruled out through randomization between the involved primary subjects; i.e., each closest farming friend was attributed to just one primary subject.

A timeline for all the project activities, including data collection and implementation, is provided in Figure 5.

$<$ Figure 5 near here>

\subsection{Theoretical hypotheses}

Our experimental design was originally developed to investigate the role of incentivized mobile money savings accounts on financial behavior and investment, while also examining the role of network adoption of mobile money on the same outcomes, and any type of interaction effects between the two interventions. 
Our first testable hypothesis is that the remunerated savings intervention (which we refer to as "the savings treatment") promotes adoption of mobile money services and particularly increases mobile savings, relative to a control group that has a mobile money account but no remuneration on its balance. As a result, this treatment should promote investment on improved inputs, with a potential impact on household expenditures because of this investment. These effects are expected to arise because the savings treatment provides experimental subjects with a clear incentive to save - which may provide farmers with the otherwise unavailable resources to invest in their farming businesses. Note that all primary experimental subjects are subject to the information modules on mKesh and on fertilizer use, which guarantee that these farmers are familiar with the specific savings treatment proposed and with the benefits of using fertilizer. Following the treatment notation introduced in Section 3.1. above, and denoting our outcome variables of interest by $Y Y$, this first testable hypothesis can be written as: $Y Y(S S)-Y Y(C C)>0$.

Our second experimental intervention is the network treatment of triplets of farming friends. It is possible that our experimental subjects faced with the network treatment change their usage of mobile money services, triggering potential changes in savings, investment and expenditure outcomes. We propose three different possible mechanisms of change.

The first proposes that subjects treated individually face more social pressure from their network connections to lend them money, as primary individuals were given a set of opportunities (the mKesh information and fertilizer modules) that is not available to their network connections. In this context, the network treatment reduces social pressure, and thereby allows treated individuals to retain more resources and increase their usage of mobile money and, in particular, their mobile savings - with ensuing potential positive impact on investment and (infrequent) expenditures.

This is what we call the social pressure mechanism. It may be written as $Y Y(N N)-Y Y(I I)>0$.

A second possibility is that primary individuals feel more confident about using mKesh services when other people in their network have mobile money accounts and are likely users as well. These farmers will therefore increase their utilization of mobile money, and may therefore increase their mobile savings balance. This is what we call the network imitation/information mechanism. ${ }^{15}$ It may be written as $Y Y(N N)-Y Y(I I)>0$.

\footnotetext{
${ }^{15}$ Note that a positive effect of the network treatment could also be due to an increased perception of the value of the network in face of the introduction of mobile money. It is however unlikely that there is an increased network externality at the level of closest (locally) farming contacts.
} 
A third possible mechanism triggered by the network treatment is related to a decrease in mobile money transaction costs and possible free-riding within the network. When the farmer network is jointly treated with access to mobile money, transaction costs for transfers are reduced. This may encourage free-riding behavior that discourages farmers from saving. Because these farmers are typically liquidity constrained, lower savings are likely to have negative consequences on their investment behavior. This is what we call the network free-riding mechanism. It may be written as $Y Y(N N)-Y Y(I I)<0$.

In line with this discussion of possible effects of the savings and network interventions, a variety of effects may arise from their combination. Specifically, if the main mechanism of change triggered by the network intervention is social pressure, we anticipate a negative interaction effect on our main outcomes of interest. However, if other mechanisms dominate, the sign of the interaction effect is unclear. ${ }^{16}$

\subsection{Sampling and assignment to treatment}

This project was implemented in the districts of Manica, Mossurize, and Sussundenga, in the Mozambican province of Manica. In each district, a set of localities, 15 in total, was identified as

having farmer associations. We asked for lists of farmers in each of the localities and surveyed these farmers in a pre-project survey. 240 farmers operating non-irrigated plots, who also provided information about their connections, were surveyed at that point in June-July 2013. Within this set of farmers, we were able to identify a set of 196 farmers in the same 15 localities with two connections each (both willing to participate in the study). These 196 farmers were interviewed during our baseline survey, which took place in July-August 2013, and form our set of primary experimental subjects. There were 392 additional farmers in our baseline sample, who form our pool of secondary experimental subjects.

Each triplet at the baseline (defined as one primary experimental subject and his/her two closest connections) was assigned to one of the four treatment groups (CI, SI, CN, SN as defined in Section

\footnotetext{
16 The savings treatment gives primary subjects access to strongly incentivized savings, which can also be used as a shield against social pressure to share resources. This could happen when $[Y(S N)-Y(C N)]$ $[Y(S I) Y(C I)]<0$, i.e., when the effect of the savings treatment on our main outcomes of interest is lower in the presence of the network treatment (than without this treatment) due to lower social pressure to share resources. The network imitation/information mechanism and the network free riding mechanism do not imply any specific sign of $[Y(S N)-Y(C N)]-[Y(S I)-Y(C I)]$.
} 
3.1. and in Figure 1). The procedure was the following. We first composed blocks of four triplets within the same locality and using observable characteristics of primary farmers collected in the pre-project survey (type of secondary occupation, whether he/she operated irrigated plots, whether he/she had used fertilizer). We then randomly assigned each member of each block to a different comparison group.

The post-intervention survey was implemented in January-February 2014, after the planting season was over, and after the urea fertilizer could be applied in that season. Of the 196 primary farmers, we were able to survey 186 individuals, which entails an attrition rate of 5\%. We check below for balance in the observable characteristics of respondents for both baseline and postintervention samples.

\subsection{Measurement}

Our measurement includes different types of data: (i) administrative data from the mobile money operator (mKesh); (ii) survey data from pre-project, baseline, and post-intervention surveys.

The administrative data from mKesh includes balance and transaction data for all experimental subjects for the relevant period of study, starting with the end of the survey team visits before planting season in 2013 to the end of June 2015, for a total period of approximately two years.

The baseline and post-intervention survey data include information on respondent and household characteristics, mobile phone use and mKesh literacy, agricultural practices, financial literacy and practices (including savings), household expenses and assets, relationship with the two connected farmers, and information on financial transfers sent/received.

\subsection{Estimation strategy}

Our empirical approach is based on estimating treatment effects on our outcome variables of interest. We now describe the main econometric specifications we employ for the estimation of these parameters.

Our design allows us to estimate average treatment effects in different ways. Most simply, the effect of interest $(\beta \beta)$ is estimated through the single-difference specification: 


$$
Y Y l l, i i, 1=\alpha \alpha+\beta \beta T T l l, i i+\varepsilon \varepsilon l l, i i, 1
$$

where $Y Y$ is an outcome of interest, $l l, i i, 1$ are identifiers for location, individual, and time period (specifically, 1 represents the follow-up measurement), $\beta \beta=\left[\beta \beta_{S S} \beta \beta_{N N} \beta \beta_{S S N N}\right]$ is the vector of effects of interest, and $T T_{l l, i i}=\left[S S_{l l, i i} N N_{l l, i i} S S_{l l, i i} \times N N_{l l, i i}\right]^{\prime}$ is a vector of dummy variables representing the treatments (savings, $S S$, and network, $N N$ ) and their interaction.

In this setting, because of the limited sample size, we add controls to our main specification: although controls do not generally change the estimate for the average treatment effect, they can help explaining the dependent variable, and therefore typically lower the standard error of the coefficient of interest. We then estimate the following core specification:

$$
Y Y l l, i, 1=\alpha \alpha+\theta \theta X X l l, i i+\beta \beta T T l l, i i+\varepsilon \varepsilon l l, i i, 1
$$

where $X X_{l l, i i}$ is a vector of location and individual (demographic) controls.

We also employ an Ancova specification, where baseline values for the dependent variable are included. We use specifications with location fixed effects, or with location fixed effects and individual controls. The latter specification is given by:

$$
Y Y l l, i i, t t=\alpha \alpha 0+\theta \theta X X l l, i i+\alpha \alpha 1 Y Y l l, i i, 0+\beta \beta T T l l, i i+\varepsilon \varepsilon l l, i i, t t
$$

where $Y Y_{l l, i i, 0}$ is the baseline value of the outcome of interest.

For ease of interpretation and transparency, we employ OLS estimations throughout the paper. Given our randomization procedure at the individual level, we estimate robust standard errors in all regressions. To address the issue of multiple hypotheses testing, we computed p-values adjusted for family-wise error rate (FWER) using the step-down multiple testing procedure proposed by Romano and Wolf (2016). This procedure improves on the ability to detect false hypotheses by capturing the joint dependence structure of the individual test statistics on the treatment impacts. For our coefficients of interest, we therefore report both naïve robust standard errors, and FWERadjusted Q-values that adjust for multiple hypothesis testing, based on 1000 simulations. 


\section{Econometric results}

\subsection{Balance}

We begin by showing balance tests for the primary farmers in the different treatment groups of our experiment. These are displayed in Tables 1 . We present average values for a wide range of observable individual characteristics of the control group in columns (1) and (6), and differences of this group to the other three groups in columns (2) - (4) and (7) - (9). We test the statistical significance of these differences, and we also test the overall significance of all differences by employing a joint F-test, for which we report p-values in columns (5) and (10). Note that in columns (1) - (5) of Tables 1, we focus on the full baseline sample of primary farmers. Because we have some attrition regarding this sample in the follow-up survey (186 out of 196 individuals were surveyed at that point), we focus on the follow-up sample in the second set of columns (6) - (10) in Tables 1 . This analysis allows us to check for differential attrition.

$<$ Tables 1 near here>

In all the 38 individual characteristics tested across the four treatment groups, we only observe small non-systematic unbalances for age, number of children, number of plots, and whether the farmer used improved seeds. These differences relative to the control group concern the network or the interaction groups. They are significant at the $10 \%$ level, except for the number of children, which is significant at the $5 \%$ level. The F-statistic on the null hypothesis of joint no differences is only rejected for the number of household members and number of children. ${ }^{17}$

In the follow-up sample, we obtain similar results: gender becomes significant for both the savings and network differences relative to the control group, and whether the farmer saves at home becomes significant for the network difference to the control group, but several statistically

\footnotetext{
${ }^{17}$ Because farmer randomization was conducted before the intervention, based on agricultural related information collected in a farmer pre-project survey prior to baseline data collection, no family characteristics were included in the randomization procedure, and there was no opportunity for enumerators in the field to change the pre-assigned treatment status of farmers. For this reason, we regard the significant differences as an outcome of chance. To ensure that this imperfect balance does not influence our experimental results, we include the number of household members and the number of children in the set of control variables we use to run all regressions. Our analysis confirms that the inclusion of these control variables in the empirical analysis does not change any of our experimental results.
} 
significant differences in the baseline disappear, namely for age, number of plots, and whether the farmer used improved seeds.

Overall, we do not detect differences across comparison groups beyond what is statistically acceptable: in the baseline, only 4 out of 114 differences tested are found to be statistically significant. In any event, we employ demographic controls in all regressions including the variables for which we found statistically significant differences across comparison groups, and results are unchanged.

An additional note goes to the characterization of our sample of primary farmers. We can observe in Tables 1 that the control group is mainly male ( 90 percent), with an average age of 43 years. Most farmers were born in the Manica province ( 92 percent), the average number of household members is 6.9 , and the average number of children is 4.3. On average, this group of farmers has been cultivating a plot for 10 years, has 2 different plots, and their main plots have 4.3 hectares. In the year before the experiment took place, 22 percent used improved seeds for maize, 16 percent used fertilizer for maize, and 76 percent of the maize produced was sold. On financerelated variables, 26 percent of farmers report having a bank account for 7 years on average; 82 percent save at home, and 14 percent contribute to a saving group. In terms of housing conditions, 25 percent of these households have an improved latrine, 28 percent have access to electricity, and 50 percent have access to piped water or a protected spring. Finally, all farmers owned a mobile phone at baseline. ${ }^{18}$

\subsection{Administrative data: mobile money savings and transactions}

We now turn to our analysis of treatment effects. ${ }^{19}$ We begin by showing results related to the use of mKesh by exploring administrative data on all transactions, including transaction type, date of

\footnotetext{
${ }^{18}$ The predominant cell phone provider in the rural areas where we worked was Movitel, a mobile phone company that does not offer mobile money services. Even though all experimental subjects owned mobile ${ }^{19}$ Note that our limited sample size has implications in terms of the statistical power available to identify treatment effects. Indeed, taking into account the actual ex-post characteristics of our sample and outcome variables, the minimum detectable treatment effects our experimental design can identify at $80 \%$ statistical power are close to our impact estimates on both mobile savings and total savings, whereas they are more comfortably lower than our estimated effects on fertilizer usage and total expenditure. Low statistical power seems more problematic in estimating the cross-randomization treatment effects on mobile savings, while our design seems marginally powered to identify cross-randomized effects on total savings and total expenditures, and adequately powered for fertilizer usage.
} 
transaction and value of transaction, made available by the mKesh operator. These results are displayed in Table 2 and Figure 6. These data concern the period from the baseline survey in 2013 (July/August 2013) to the end of June 2015, spanning approximately two years. We start by examining the log average daily savings in mKesh (distinguishing between the first and the second years of data), while also looking at the different types of mKesh transactions - specifically, cashins, transfers received, transfers sent, payments, airtime top-ups, and cash-outs. Importantly, note that trial transactions made as part of the information module introducing mobile money to farmers are excluded from our analysis.

In Table 2, we examine single treatment-control difference specifications for the sample of primary farmers, since there is no available baseline mKesh - as mobile money was not previously available in the rural areas where we worked. For each year with available data, we test two main specifications: one where we separately estimate the impact of the incentivized savings intervention and of the network intervention - columns (1) - (2) and (5) - (6) of Table 2 - and another where, in addition to estimating the impact of the two main interventions, we explicitly identify the impact of the interaction between the savings and the network interventions - columns (3) - (4) and (7) (8) of Table 2. For each of these specifications, we estimate two versions: one controlling only for district fixed effects, and a second adding individual controls. ${ }^{20}$

phones, they only worked with Movitel sim cards because the mobile phones were blocked from usage in other networks. Because we were working with mobile money brand mKesh, which only worked on a different mobile phone network, we needed farmers to be able to operate a different sim card. Hence, the need for our project to provide cell phones to all experimental subjects in our sample even if they already owned a phone.

<Table 2 near here>

As shown in columns (1) and (2) of Table 2, we obtain that the savings treatment significantly increased average daily savings in mKesh by 32 percent in the first year of the experiment, when the experimental savings account was active. This effect is specifically for the sample of primary experimental farmers that received the savings treatment, regardless of whether they received or not the network treatment. If we focus on those that only received the savings treatment, the magnitude of this effect increases to 38-44 percent, statistically significant at the 5 or $10 \%$ levels,

\footnotetext{
${ }^{20}$ Individual controls include basic demographic variables: gender, age, whether the individual was born in Manica province, whether the individual has completed primary school, number of household members,
} 
as shown in columns (3) and (4) of Table 2. Note that the point estimates for the effect of the savings intervention in the second year shown in columns (5)-(8) are still positive and sizeable, even though no longer statistical significant. The network intervention and its interaction with the savings intervention do not have a clear impact on mobile savings: all our estimates of this impact have a negative sign, but cannot be precisely estimated.

We interpret these estimates as supportive of the effectiveness of the incentivized mobile savings intervention in promoting savings, as expected from our theoretical hypothesis. The savings incentive provided by the bonus on mobile savings seems to be short-lived, suggesting that farmers responded to the bonus incentive only while it lasted. It is therefore likely the case that farmers are not constrained because they lack access to safe saving alternatives, but instead allocate available resources wherever they get the highest return.

In order to explain how the increased mobile savings level was achieved by the incentivized savings intervention, we examine the impact of the different treatments on the log value of the different types of transactions - displayed in Figure 6. The different types of transactions examined using the administrative records from the mobile money company include cash-ins to the mKesh account, transfers received via the mKesh system to the respondent's account, transfers sent via mKesh from the respondent's account, in-store payments made using mKesh, airtime top-ups purchased through mKesh, and cash-outs from the respondent's mKesh account. As shown in Panel A, the incentivized savings treatment produced a significant positive $94 \%$ increase in the value of transfers received. The increased transfers received account for most of the increase in mKesh savings as other inflows into the system (cash-in's) have a positive point

$\overline{\text { and number of children. We also estimated specifications using different sets of controls and our main results }}$ are unchanged.

estimate that is not statistically significant (at the 5\% level), whereas all mKesh outflows have point estimates very close to zero. ${ }^{21}$ We interpret these results as evidence that the farmers in the savings treatment were able to raise funding via remote mKesh transfers to increase their average mobile money balances. These transfers are likely to have been received from mobile money users in urban areas of the country where mKesh was already operating. Note that there are substantial internal migration flows from the rural areas of the Manica province (where this project took place) to

\footnotetext{
${ }^{21}$ In terms of monetary amounts, note that the average amount received as a transfer via mKesh was 41 meticais. This implies that the estimated 94\% savings treatment effect depicted in Figure 6 is very much in line with the $32 \%$ increase in savings by individuals in the savings treatment group relative to a control group where average savings was 87 meticais.
} 
Chimoio (the capital city of the Manica province), and to Maputo (the capital city of the country). This interpretation is consistent with the number and magnitude of mKesh transfers sent by other farmers in our sample being rather low (much lower than for transfers received), and also with no evidence of substantial mobile money take-up outside of our sample in the rural areas where the service was introduced for the purpose of this project. Unfortunately, we cannot further support our interpretation of these results with evidence from the administrative data because information on the senders of the mKesh transfers received by the farmers in our sample is not available.

Panel B of Figure 6 shows that the sample of individuals receiving the network treatment did not exhibit systematic statistically significant differences in their mobile money transactions relative to the control group. Consistent with the negative point estimate on the average mobile savings of these farmers, we however note a significant increase in the value of mKesh transfers sent by farmers subject to the network intervention. ${ }^{22}$ This effect may be the result of the reduction in transaction costs allowed by mobile money, which can trigger free-riding behavior by farmers subject to the network treatment as explained in our discussion of the potential theoretical hypotheses.

\section{$<$ Figure 6 near here>}

\subsection{Survey-based measures: savings and transfers}

We now examine survey measures of savings to complement our analysis of mobile savings. In Table 3 we show treatment effects on the intensive margin of aggregate savings - in log value at the time of surveying. This measure adds together several reported measures of savings, namely savings kept at home, in a bank account, with a local shopkeeper, and with friends or family. Hence, we are including here the main alternatives to saving in mKesh. Since we have baseline data available for savings, we estimate Ancova specifications including both district dummies and full individual controls.

\footnotetext{
${ }^{22}$ Note, however, that the average value of transfers sent via mKesh is only 14 meticais. This small magnitude is consistent with the non-significant negative $12 \%$ impact of the network treatment on average savings reported in Table 2.
} 
<Table 3 near here>

We expect the savings treatment effect not to be as clearly positive as it is for mKesh savings: it could even be negative if there is substitution between savings in mKesh and other types of savings. Indeed, the savings treatment has a positive impact on the aggregate value of savings, but this is not as precisely estimated as the effect on the value of mKesh savings. As shown in Table 3, the impact of the savings treatment on aggregate savings is only marginally statistically significant (at the $10 \%$ level) when considering the full sample of primary experimental subjects that received the savings treatment, including those who were subject to the network intervention: the magnitude of this effect is 76 percent. This effect is stronger for those who received both the savings and the network treatment, but it is not statistically significant after accounting for multiple hypotheses testing.

We estimate negative effects of the network treatment on aggregate savings of primary farmers between 67 and 72 percent for the full sample subject to the network treatment, including those also given the savings treatment. However, these effects are not statistically significant after accounting for multiple hypotheses testing. This negative impact is consistent with the negative point estimates of the effect of the network treatment on mKesh savings, and may be due to some form of freeriding on network savings, as described in our discussion of the theoretical motives potentially driving our results. Note that the negative impact of the network treatment on savings is counteracted when this intervention is implemented together with the savings intervention: the interaction effect of these two interventions is actually positive, although not statistically significant after accounting for multiple hypotheses testing. This interaction is evidence against the network treatment acting as a shield against social pressure, and is consistent with both network imitation/information mechanisms and with the free-riding hypothesis discussed in Section 3.3.

In order to understand the mechanisms underlying the impact of our experimental interventions on aggregate savings, we examine the behavior of transfers received and sent, as reported in the baseline and follow-up surveys. Figures 7 display the Ancova point estimates and confidence intervals at the 5\% confidence level.

<Figures 7 near here> 
We expect the savings treatment to increase transfers received and to decrease transfers sent, as farmers respond to the savings incentives that provide them with an attractive option for their savings. The estimates displayed in Panels A of Figures $7 \mathrm{a}$ and $7 \mathrm{~b}$ are consistent with our hypothesis for transfers received - the likelihood of receiving a transfer increases for treated farmers, although the positive point estimate for the value of transfers received is small and not statistically significant. Transfers sent do not seem to respond to the savings treatment. ${ }^{23}$

When considering the treatment group that was subject to the network intervention, we find a strong negative effect on both the likelihood and the value of transfers received, while transfers sent do not seem to be significantly affected. These results provide at least partial explanation for the decrease in savings observed for farmers subject to the network intervention.

\subsection{Agricultural inputs}

We now report the treatment effects related to the use of agricultural inputs by the primary experimental farmers in our sample. Table 4a shows the effects on synthetic fertilizer use (as reported in the endline survey about the previous season), both in terms of extensive and of intensive (measured in kilograms) margins. Table 4a also displays treatment effects on knowledge about using urea fertilizer. This is assessed through an index of four equally weighted binary variables constructed from four different survey questions: one asking about the appropriate distance to the plant for the application of fertilizer; one asking about the appropriate

depth for the application of fertilizer; one asking about the appropriate quantity of fertilizer per plant; and one asking about the appropriate timing for the application of fertilizer. Table $4 \mathrm{~b}$ additionally presents the estimated effects of the randomized interventions on the use of improved seeds, number of workers employed in the subject's farm, and on ownership of irrigation pumps. All data on these outcomes were obtained from the endline survey questions about the use of inputs in the previous season.

We estimate single-difference or Ancova specifications depending on the baseline data availability of each outcome variable. Baseline data are available, and so Ancova estimation is used for fertilizer

\footnotetext{
${ }^{23}$ In face of the savings treatment, farmers not exposed to the network treatment could possibly share access to the new savings account with their closest friends. Evidence on borrowing from closest farming friends suggests that possibility did not materialize.
} 
use (extensive margin), improved seeds use (extensive margin), number of workers employed in farm, and irrigation pumps ownership. For the remaining outcomes, we employ single-difference specifications.

<Tables 4 near here>

We theoretically expected the savings treatment to produce a clear positive effect on the take-up of fertilizer. Table 4a confirms this hypothesis. We find that the likelihood that fertilizer was used clearly increased with the savings treatment. This effect ranges between 34 and 36 percentage points, when considering the whole sample including those facing the network treatment in addition to the savings treatment, and between 28 and 31 percentage points for farmers in the sample not facing the network intervention. This effect is significant at the $1 \%$ level for all specifications, even after adjusting for multiple hypotheses testing. We also find statistically significant positive treatment effects between $13.8 \mathrm{Kg}$ and $14.6 \mathrm{Kg}$ on the intensive margin of fertilizer use, when considering all primary subjects offered the incentivized mobile savings account including those also facing the network treatment. This is clear evidence indicating that the savings treatment was particularly effective at increasing fertilizer use.

As explained in the description of the experimental implementation, the research team mediated purchases of fertilizer in the rural areas where the experiment took place - which made it available for purchase to all treated and control farmers in the sample. The research team also distributed saving bonuses in fertilizer. A valid concern is therefore that the positive savings treatment effect on fertilizer use is driven by the distribution of fertilizer by the research team - either through saving bonuses, or by fertilizer sales. This concern is however mitigated by the fact that the average report of urea fertilizer acquired was $47.3 \mathrm{Kg}$ in the endline survey, while the average quantity of urea fertilizer given in bonuses for the savings treatment was $0.9 \mathrm{Kg}$, and the average quantity of urea fertilizer purchased from the research team was $2.8 \mathrm{Kg}$. We also note that in the group of farmers that received a bonus in fertilizer, i.e., through the savings treatment, only 51 percent reported having used fertilizer. In face of this evidence, it is unlikely that the impact of the savings treatment on fertilizer use was driven by the fertilizer distributed as saving bonuses, or by the fertilizer available for sale through the research team.

Instead, it is more likely the case that the savings treatment prompted inattentive farmers to focus on this incentivized agricultural technology, as in Karlan et al. (2016). Note that the savings treatment including a bonus paid in fertilizer, offered right after harvest, the time of the year when 
farmers have most financial resources available, may have raised farmers' (limited) attention to saving some of these recent harvest proceeds in order to invest in fertilizer. Similarly, it is plausible that farmers also became more attentive to the information on fertilizer usage that was provided at the time the fertilizer bonus was offered, thereby generating the positive treatment effect of the savings treatment on knowledge about how to use the fertilizer. This is consistent with a statistically significant positive effect of the savings treatment on the likelihood of knowing about how to use urea fertilizer ranging between 13 and 18 percentage points.

While there is no clear pattern on the interaction effects of the savings and network interventions together on the use of or knowledge about fertilizer, there is a pattern of a negative impact of the network intervention alone on all agricultural outcomes - although these effects are never precisely estimated when adjusting for multiple hypotheses testing. Still, if we take the consistent negative sign as an indication of some economic content (which we cannot precisely estimate likely because our experimental design does not provide adequate statistical power), this negative effect can be interpreted as a result of free-riding according to the theoretical hypothesis we discuss in Section 3.3: farmers who are treated jointly with their network may think they do not need to save for fertilizer purchases because they will be able to free-ride on others' savings, the end result being that they cannot afford to use the fertilizer.

The strong statistical significance (at the $1 \%$ level) of the positive sum of all estimated coefficients together implies that the strength of the investment effects of the savings incentives intervention is larger than any potential negative free-riding effects (net of imitation or social pressure shield effects) arising from the network treatment.

We also tested whether our experimental interventions may have affected agricultural investment in agricultural inputs other than fertilizer. The theoretical hypothesis would be that the experimental interventions had an effect on agricultural investment in general, including on investment that complements fertilizer usage (including use of improved seeds, hiring of farm workers and use of irrigation pumps), even if this was not directly mentioned in any of the interventions the farmers were exposed to. This type of spillover investment could be expected if farmers were not investing in their agricultural activity because they were unable to save.

Table $4 \mathrm{~b}$ shows however that the incentivized savings treatment did not have any significant impact on using improved seeds, employing more workers in the farm, or owning irrigation pumps. These results seem to indicate that, more than financially constrained, the farmers may generally have 
limited attention to investment in fertilizer and other modern agricultural techniques. The focused incentives on technology adoption offered by the fertilizer-bonus paid in the savings treatment may have served as a "reminder" to save from the recent harvest proceedings, so that adoption of fertilizer technology only took place.

\subsection{Household expenditure}

Table 5 presents treatment effects for different types of household expenditure, specifically daytoday and non-frequent expenditures, as well as total expenditures. These data were collected in both the baseline and endline surveys conducted before and after our experiment. We estimate Ancova specifications to measure treatment effects.

$<$ Table 5 near here>

We expect that the intervention offering the remunerated mKesh savings account increases the level of non-frequent expenditures more strongly than the level of day-to-day expenditures. This is because it is more likely that increased savings are used for buying non-frequent goods and services, including agricultural inputs. This hypothesis is confirmed by the results shown in Table 5. Indeed, the savings treatment increased non-frequent expenditures between 48 and 51 percent - and by even more (between 58 and 63 percent) when considering the sample that was not given access to the network treatment. These are statistically significant effects at the 1 and 5\% levels. Day-to-day expenditures yield smaller positive effects of the savings treatment, that are only statistically significant at the $10 \%$ level when considering the whole sample of farmers that received the savings treatment, including those who also received the network treatment.

Overall, this is evidence that the savings treatment was more effective at increasing non-frequent purchases of goods and services. We also find robust effects of the savings treatment on total expenditures. The magnitude of these effects ranges between 69 and 77 percent for the sample without the network treatment, and between 60 and 69 percent for the sample including the network treatment, all of these effects being statistically significant at the $1 \%$ level.

The network treatment had no substantial or statistically significant effect on any type of expenditures, similarly to the effect of the interaction between savings and network interventions. 


\section{Concluding remarks}

This paper evaluates the impact of a randomized field experiment where a remunerated mobile money savings account was introduced to smallholder farmers in rural Mozambique. Consistent with our theoretical hypothesis, we find that access to the mobile savings account increased the amount of money saved using mobile money, at least while interest was being paid on mobile money balances. This increase in savings is obtained at least partially via increased transfers being received, particularly via mobile money, likely from outside of the village network.

This incentivized savings intervention promoted agricultural investment, namely the likelihood of using fertilizer, which increased by about 30 percentage points. We find however that farmers benefiting from the savings treatment did not increase investment in other technologies that complement fertilizer usage (such as use of improved seeds, hiring of farm workers and use of irrigation pumps), and which, unlike fertilizer, were not directly mentioned in any of the interventions the farmers were exposed to. These results suggest the importance of fertilizer salience in our savings treatment: since the savings treatment included a bonus paid in fertilizer, offered right after harvest, the time of the year when farmers have most financial resources available, we argue that this fertilizer bonus may have acted as a "reminder" and focused farmers' (limited) attention to saving some of the recent harvest proceeds in order to invest in fertilizer.

This evidence, together with the fact that mobile savings only increased while interest was being paid on its balance, leads us to believe that more than being financially constrained by a lack of alternative ways to save, the farmers we worked with may generally have limited attention to investment in fertilizer and other modern agricultural techniques.

The experiment also varied whether close farming friends were given access to the same opportunities offered to primary experimental subjects. Beyond the savings account, these opportunities included being introduced to mobile money and given information about fertilizer use. The effects of this network intervention on savings and investment are less strong and clear to interpret than those of the incentivized savings intervention. The network treatment decreased savings (especially for those farmers who did not receive any savings incentive) and may also have reduced fertilizer usage (although this effect cannot be precisely estimated). No statistically significant effect on expenditures could be detected. These results are consistent with the network treatment giving rise to network free-riding effects, where treated farmers save less because the network access to mobile money reduced the transactions costs of transfers thereby discouraging 
saving behavior. Alternative hypotheses such as the network treatment shielding farmers from social pressure or promoting network information/imitation do not gather empirical support from our experiment. It would however be interesting to design further experiments that can distinguish more explicitly between the different potential mechanisms underlying this type of network treatment.

This piece of research shows that mobile money can be used as a platform to incentivize adoption of modern agricultural technologies such as fertilizer, when it is adequately tailored. Other research such as Batista and Vicente (2018) showed that on its own, the simple availability of mobile money services does not lead to agricultural modernization or business investment. Our work shows that increasing the salience of a beneficial technology at a time when farmers are not financially constrained may prompt them to save and invest in that specific technology. However, because our experimental design incentivized savings by paying interest in the form of fertilizer, and the whole experiment was framed around saving for the specific purpose of fertilizer usage, we cannot be sure that providing regular interest in cash or designing an intervention with more general framing would have obtained the same positive effects on fertilizer usage or, more broadly, on the adoption of other beneficial technologies.

Since many central banks in developing countries regard mobile money as a risky innovation, in need of tight regulation, many promising possibilities of mobile money are still not allowed. Our evidence suggests that enabling remunerated saving accounts to be offered through mobile money platforms may be a promising pro-poor policy. In order to inform policymakers, additional research may examine the impact of different possibilities to implement remunerated mobile savings - for example, comparing in-kind vs. interest-bearing mobile saving accounts relative to already tested saving alternatives, such as locked saving boxes or commercial bank accounts. 


\section{References}

Aker, Jenny, Rachid Boumnijel, Amanda McClelland, and Niall Tierney (2016), Payment Mechanisms and Anti-Poverty Programs: Evidence from a Mobile Money Cash Transfer Experiment in Niger, Economic Development and Cultural Change, 65(1), pp. 1-37;

Ashraf, Nava, Dean Karlan, and Wesley Yin (2006), Tying Odysseus to the Mast: Evidence from a Commitment Savings Product in the Philippines, Quarterly Journal of Economics, 121(2), pp. 635-672;

Baland, Jean-Marie, Catherine Guirkinger, and Charlotte Mali (2011), Pretending to Be Poor: Borrowing to Escape Forced Solidarity in Cameroon, Economic Development and Cultural Change, 60(1), pp. 1-16;

Batista, Catia, and Pedro C. Vicente (2018), Is Mobile Money Changing Rural Africa? Evidence from a Field Experiment, NOVAFRICA Working Paper 1805;

Batista, Catia, and Pedro C. Vicente (2020), Adopting Mobile Money: Evidence From An Experiment In Rural Africa, American Economic Review P\&P, forthcoming;

Batista, Catia, Sandra Sequeira, and Pedro C. Vicente (2019), Mobile Money, Business Training and Microenterprise Development in Mozambique, NOVAFRICA Working Paper;

Batista, Catia, Gharad Bryan, and Dean Karlan (2018), Learning-by-testing: The benefits of involving farmers directly in experimenting with new agricultural practices, London School of Eonomics, International Growth Center Policy Brief;

Beaman, Lori, Ariel Ben Yishay, Jeremy Magruder, and Mushfiq Mobarak (2015), Can Network Theory- based Targeting Increase Technology Adoption?, Northwestern University, mimeograph;

Ben Yishay, Ariel, and Mushfiq Mobarak (2018), Social Learning and Incentives for Experimentation and Communication, Review of Economic Studies, forthcoming;

Blumenstock, Joshua, Michael Callen, and Tarek Ghani (2018), Why Do Defaults Affect Behavior? Experimental Evidence from Afghanistan, American Economic Review, 108(10): pp. 28682901 ;

Brune, Lasse, Xavier Giné, Jessica Goldberg, and Dean Yang (2016), Facilitating Savings for Agriculture: Field Experimental Evidence from Malawi, Economic Development and Cultural Change, 64(2), pp. 187-220;

Carter, Michael R., Rachid Laajaj, and Dean Yang (2013), The Impact of Voucher Coupons on the Uptake of Fertilizer and Improved Seeds: Evidence from a Randomized Trial in Mozambique, American Journal of Agricultural Economics, 95(5), pp. 1345-1351;

Conley, Timothy G., and Christopher R. Udry (2010), Learning About a New Technology: Pineapple in Ghana, American Economic Review, 100(1), pp. 35-69;

Cunguara, Benedito, and Ika Darnhofer (2011), Assessing the Impact of Improved Agricultural Technologies on Household Income in Rural Mozambique, Food Policy, 36, pp. 378-390;

De Janvry, Alain, Elisabeth Sadoulet, and Tavneet Suri (2017), Field Experiments in Developing Country Agriculture, in Handbook of Field Experiments, edited by Abhijit Banerjee and Esther Duflo, pp. 427-466, Amsterdam, Netherlands: Elsevier;

De Mel, Suresh, Craig McIntosh, Ketki Sheth, Christopher Woodruff (2018), Can Mobile-Linked Bank Accounts Bolster Savings? Evidence from a Randomized Controlled Trial in Sri Lanka, NBER Working Paper No. 25354. 
Duflo, Esther, Michael Kremer, and Jonathan Robinson (2011), Nudging Farmers to Use Fertilizer: Theory and Experimental Evidence from Kenya, American Economic Review, 101, pp. 23502390;

Dupas, Pascaline, and Jonathan Robinson (2013a), Why Don't the Poor Save More? Evidence from Health Savings Experiments, American Economic Review, 103(4), pp. 1138-1171;

Dupas, Pascaline, and Jonathan Robinson (2013b), Savings Constraints and Microenterprise Development: Evidence from a Field Experiment in Kenya, American Economic Journal: Applied Economics, 5(1), pp. 163-192;

Dupas, Pascaline, Dean Karlan, Jonathan Robinson, and Diego Ubfal (2018), Banking the Unbanked? Evidence from Three Countries, American Economic Journal: Applied Economics, 10(2), pp. 257-297;

Goldberg, Jessica (2017), The Effect of Social Pressure on Expenditures in Malawi, Journal of Economic Behavior and Organization, 143, pp 173-185;

Jack, William, and James Habyarimana (2018), High Hopes: Experimental Evidence on Saving and the Transition to High School in Kenya, Georgetown University, mimeograph;

Jack, William, Adam Ray, and Tavneet Suri (2013), Transaction Networks: Evidence from Mobile Money in Kenya, American Economic Review, Papers and Proceedings, 103(3), pp. 356-361;

Jack, William, and Tavneet Suri (2011), Mobile Money: The Economics of M-PESA, NBER Working Paper No. 16721;

Jack, William, and Tavneet Suri (2014), Risk Sharing and Transactions Costs: Evidence from Kenya's Mobile Money Revolution, American Economic Review, 104(1), pp. 183-223;

Jack, William, and Tavneet Suri (2016), The Long Run Poverty and Gender Impacts of Mobile Money, Science, 354(6317), pp. 1288-1292;

Jakiela, Pamela, and Owen Ozier (2016), Does Africa Need a Rotten Kin Theorem? Experimental Evidence from Village Economies, Review of Economic Studies, 83(1), pp. 231-268;

Karlan, Dean, Margaret McConnell, Sendhil Mullainathan, and Jonathan Zinman (2016), Getting to the Top of Mind: How Reminders Increase Saving, Management Science, 62(12): 33933411.

Mbiti, Isaac, and David N. Weil (2011), Mobile Banking: The Impact of M-PESA in Kenya, NBER Working Paper No. 17129;

Riley, Emma (2018), Mobile Money and Risk Sharing against Village Shocks, Journal of Development Economics, 135, pp 43-58;

Romano, J. P. and M. Wolf (2016), Efficient computation of adjusted p-values for resampling based stepdown multiple testing, Statistics \& Probability Letters, 113, pp. 38-40.

Appendix

Figure 1: 2x2 experimental design

\begin{tabular}{|c|c|c|}
\hline & Individual Treatment - I & Network Treatment - N \\
\hline Control - C & CI & CN \\
\hline Savings Treatment - S & SI & SN \\
\hline
\end{tabular}


Figure 2: mKesh leaflet Front.

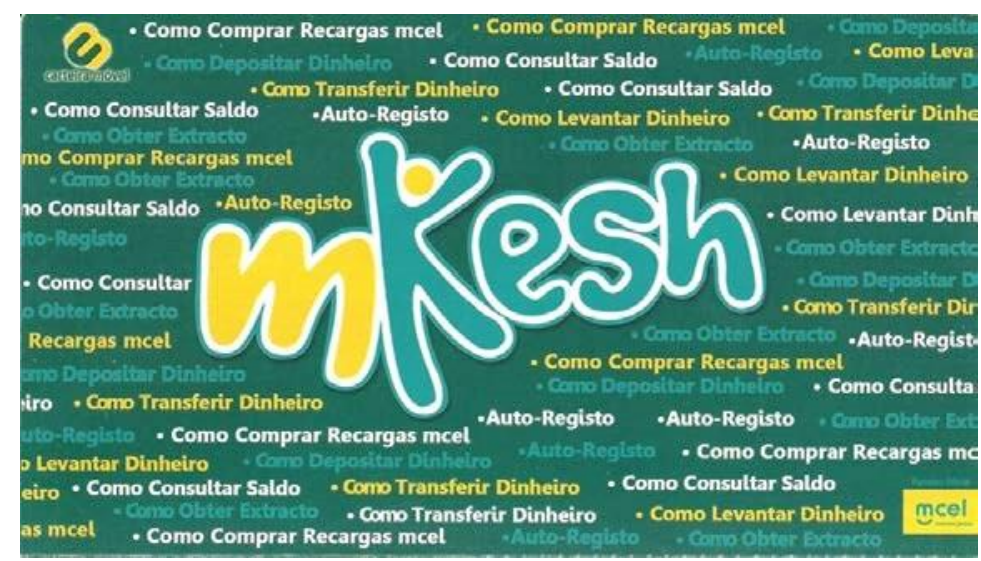

Main operations conducted:

Self-registration.

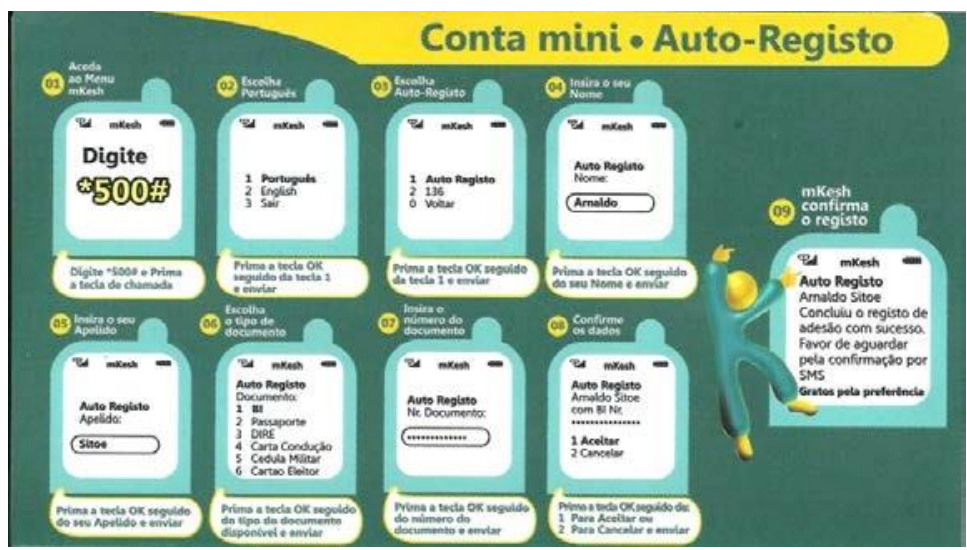

Deposit.

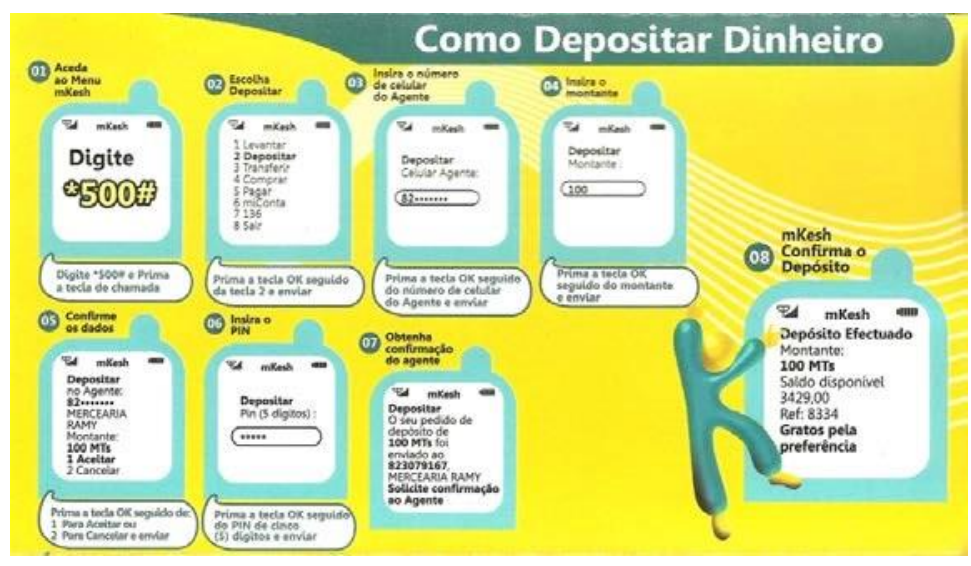


Figure 3: Leaflet on fertilizer use

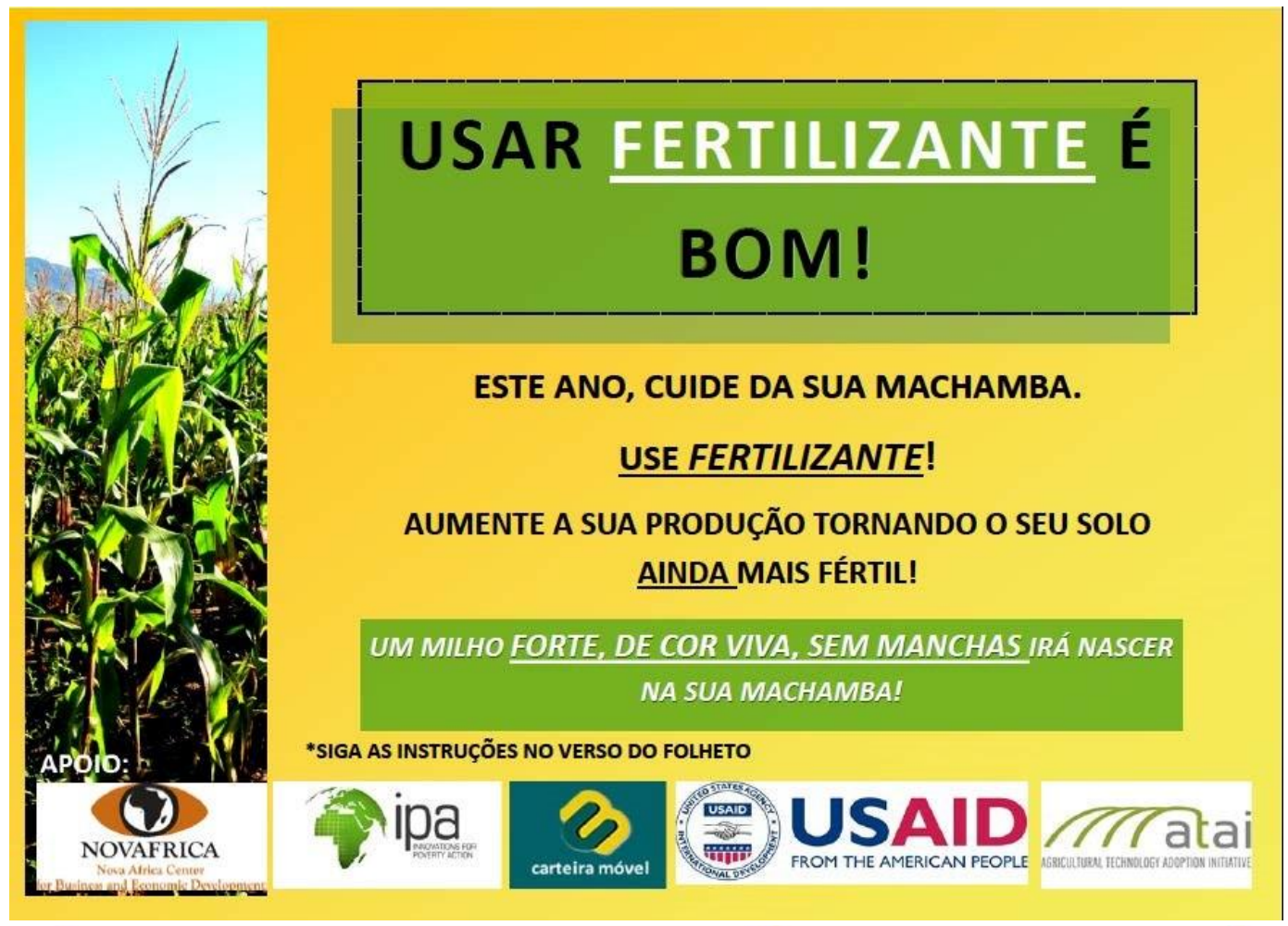

\begin{tabular}{|c|c|c|}
\hline \multicolumn{3}{|c|}{ O QUE O SENHOR SABE E FAZ BEM... } \\
\hline 1 & PREPARAR O SOLO. & $\begin{array}{l}\text {-Remoção da vegetação existente. } \\
\text {-Deixar o capim acumular no terreno (até } 30 \mathrm{~cm} \\
\text { de altura). }\end{array}$ \\
\hline 2 & SEMENTEIRA & $\begin{array}{l}\text {-Esperar as primeiras chuvas e fazer sementeira } 4 \\
\text { dias depois destas. Não deixe passar esta altura! } \\
\text {-Fazer sementeira directa, ou seja, mexer na } \\
\text { coberta da terra apenas no local de semeio. Isto } \\
\text { evita que o seu terreno fique exposto. } \\
\text {-Mesmo em solos férteis, é benéfico o uso de } \\
\text { adubos orgânicos como por exemplo o estrume de } \\
\text { boi. }\end{array}$ \\
\hline 3 & SACHA & $\begin{array}{l}\text {-Retire as ervas daninhas da machamba para que } \\
\text { não prejudiquem a qualidade do solo e dessa } \\
\text { forma a quantidade de milho aumente. }\end{array}$ \\
\hline 4 & $\begin{array}{l}\text { ADUBAÇÃO/ } \\
\text { FERTILIZANTE }\end{array}$ & $\begin{array}{l}\text {-Use fertilizante de topo, UREIA, porque apesar da } \\
\text { elevada fertilidade dos solos de Moçambique, } \\
\text { existem processos da natureza que ao longo do } \\
\text { tempo vão prejudicando a machamba. } \\
\text {-Mantenha as caracteristicas naturais do solo } \\
\text { enquanto aumenta os niveis de produção! }\end{array}$ \\
\hline
\end{tabular}

\section{O QUE PODE FAZER MELHOR...}

Use um fertilizante de topo: UREIA.

Esta é importante mesmo que o solo seja fértil. A Ureia é rica em nitrogénio que é um componente vital para a vida da planta e que é escasso nos solos de Moçambique.

Assim sendo, 2 a 3 semanas após a germinação espere pela chuva. Quando esta cessar, aplique ureia no seu milho, conforme indicado na figura.

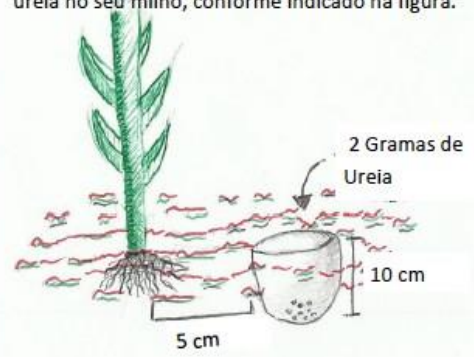

Este fará o seu Milho crescer forte, com cores vivas e sem manchas!

EXPERIMENTE ESTA CAMPANHA EM 0,25HECTARES E VEJA A DIFERENÇA! 
Figure 4: Leaflet on savings bonus

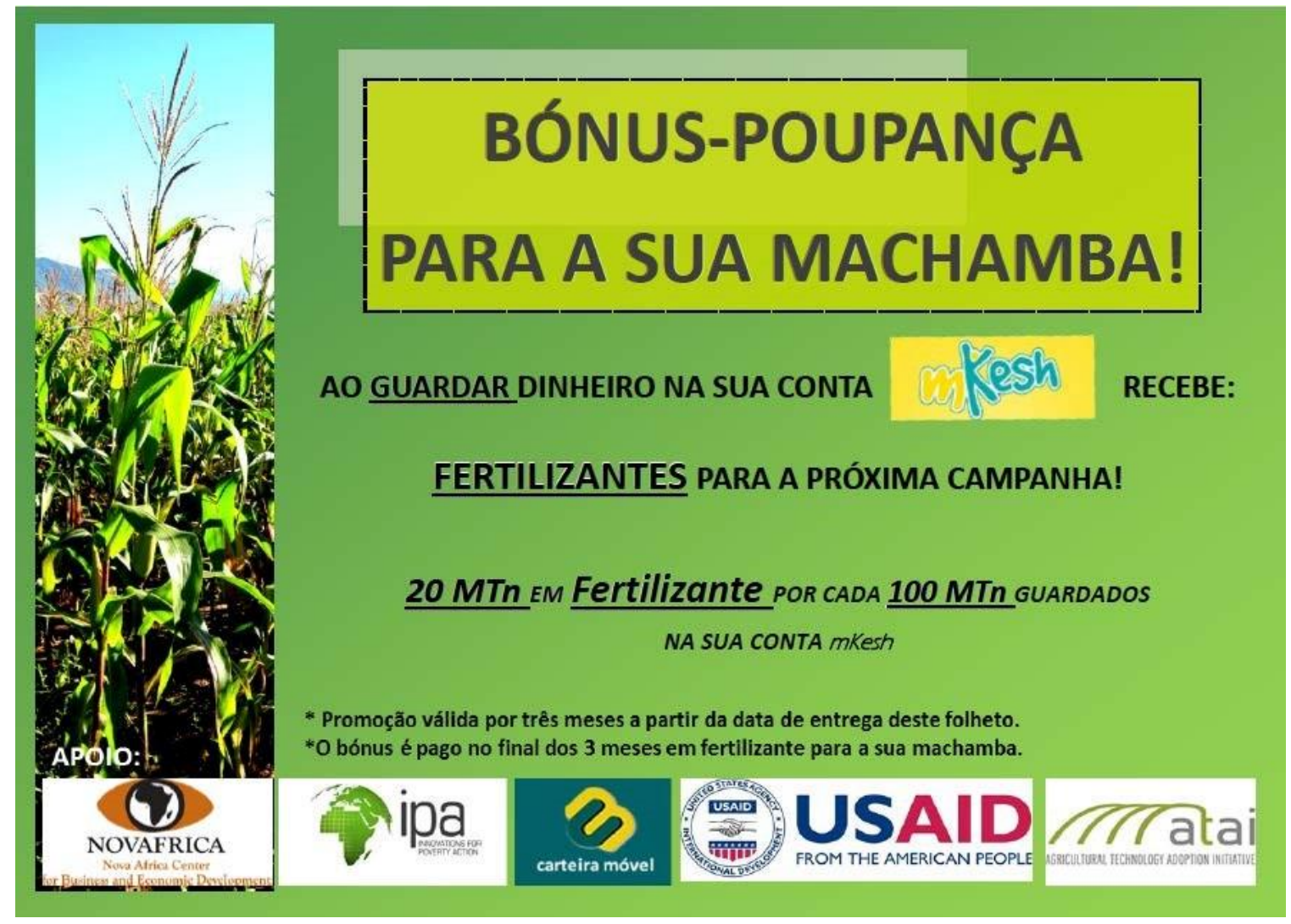

Figure 5: Project timeline

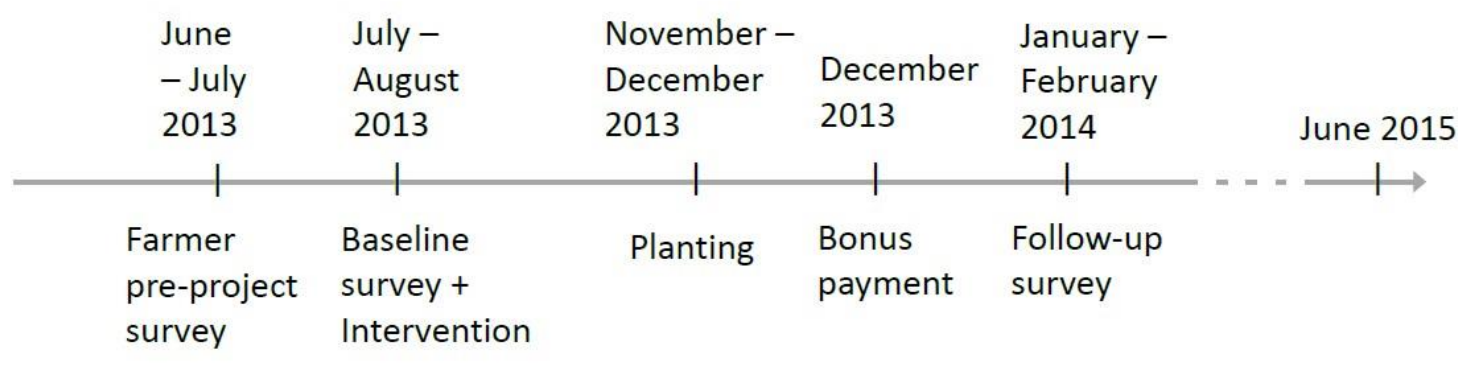

Administrative data available 
Figure 6: log value of mKesh transactions - administrative data
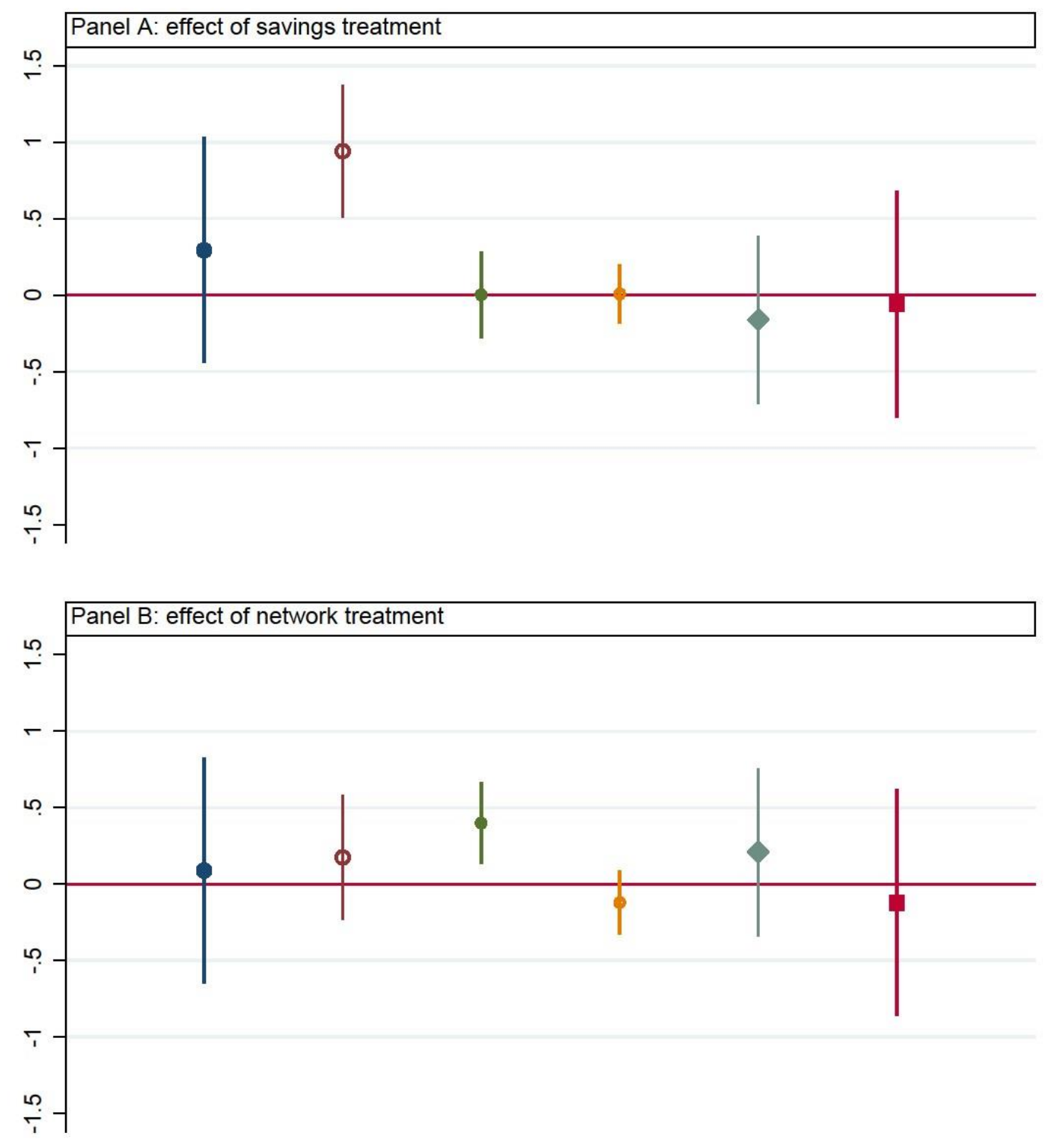

\section{- cash-ins \\ 0 mKesh transfers received

$\begin{array}{ll}\text { - mKesh transfers sent } & \text { top-ups } \\ \text { - payments } & \text { cash-outs }\end{array}$

Note: Treatment effects relative to the control group estimated using OLS. Dependent variable is log value of mKesh transactions between July 2013 and June 2015. All regressions include district fixed effects. Controls are gender, age, whether the individual was born in Manica province, whether the individual has completed primary school, number of household members, and number of children. Robust standard errors reported. 
Figure 7a: Likelihood of transfers - survey data
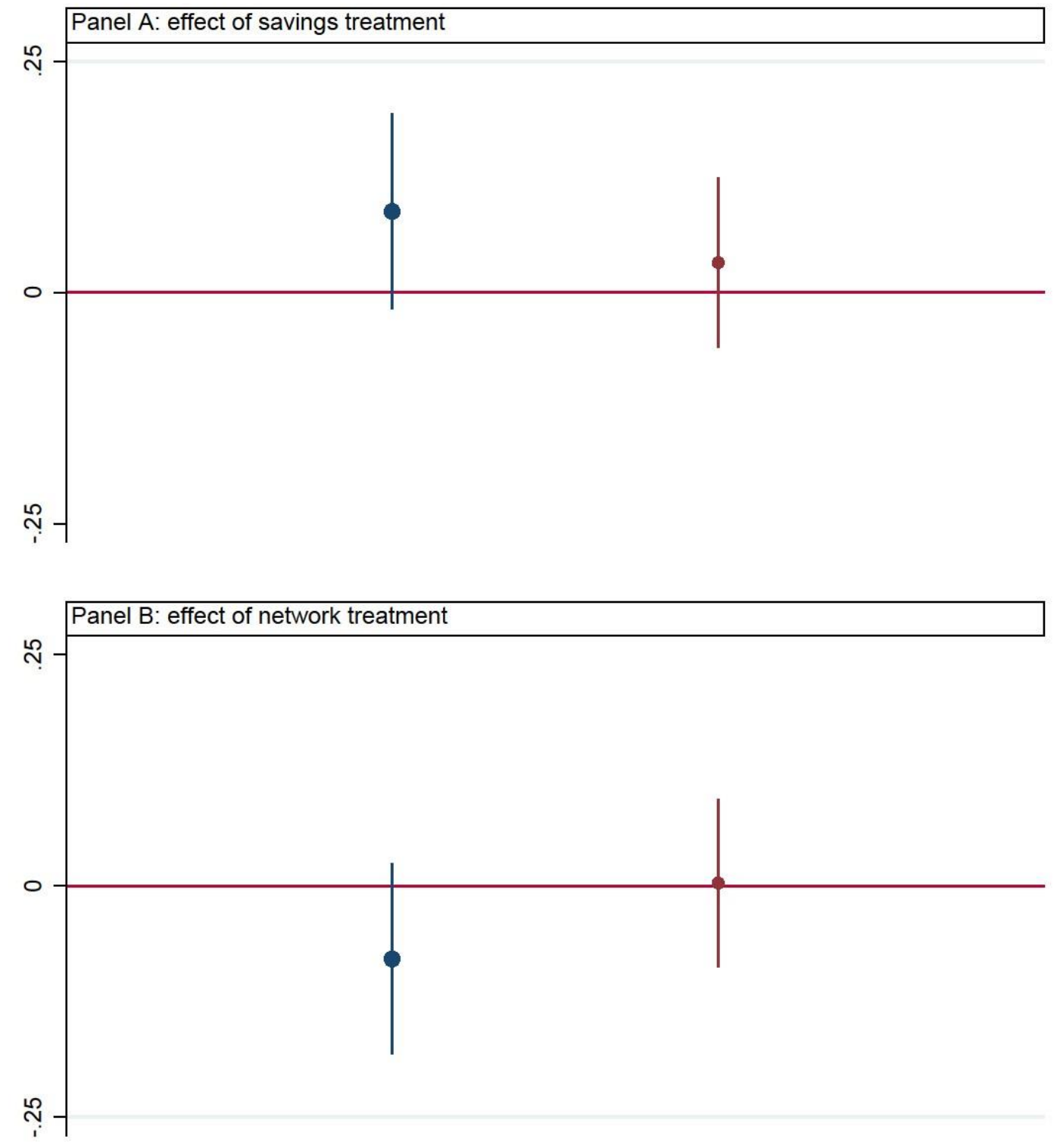

Note: Treatment effects relative to the control group estimated using ANCOVA. Dependent variable is binary and refers to whether a transfer was received/sent or not, according to survey data. All regressions include district fixed effects. Controls are gender, age, whether the individual was born in Manica province, whether the individual has completed primary school, number of household members, and number of children. Robust standard errors reported. 
Figure $7 \mathrm{~b}$ : Value of transfers in meticais - survey data
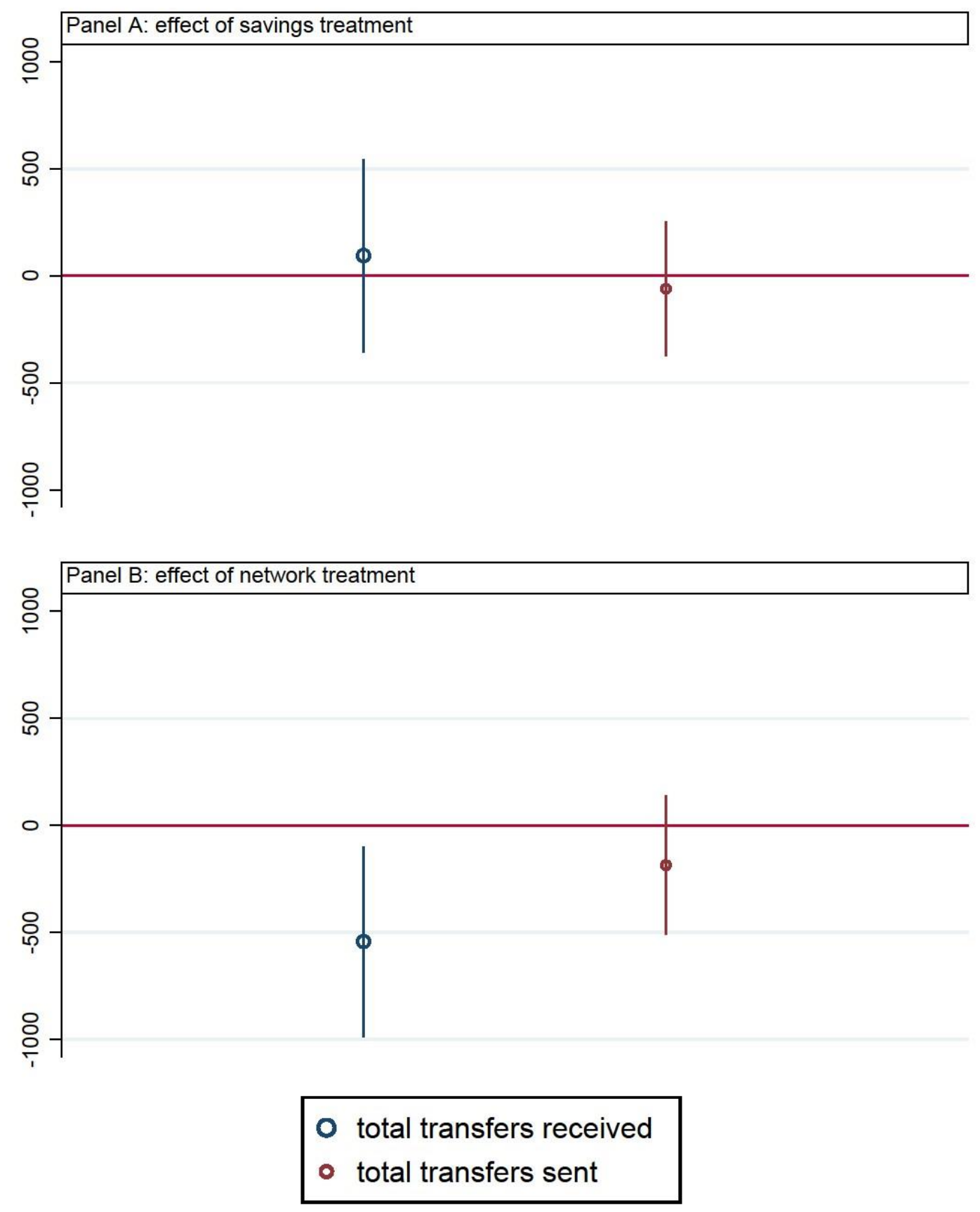

Note: Treatment effects relative to the control group estimated using ANCOVA. Dependent variable is value in meticais of transfers received/sent or not, according to survey data. All regressions include district fixed effects. Controls are gender, age, whether the individual was born in Manica province, whether the individual has completed primary school, number of household members, and number of children. Robust standard errors reported. 


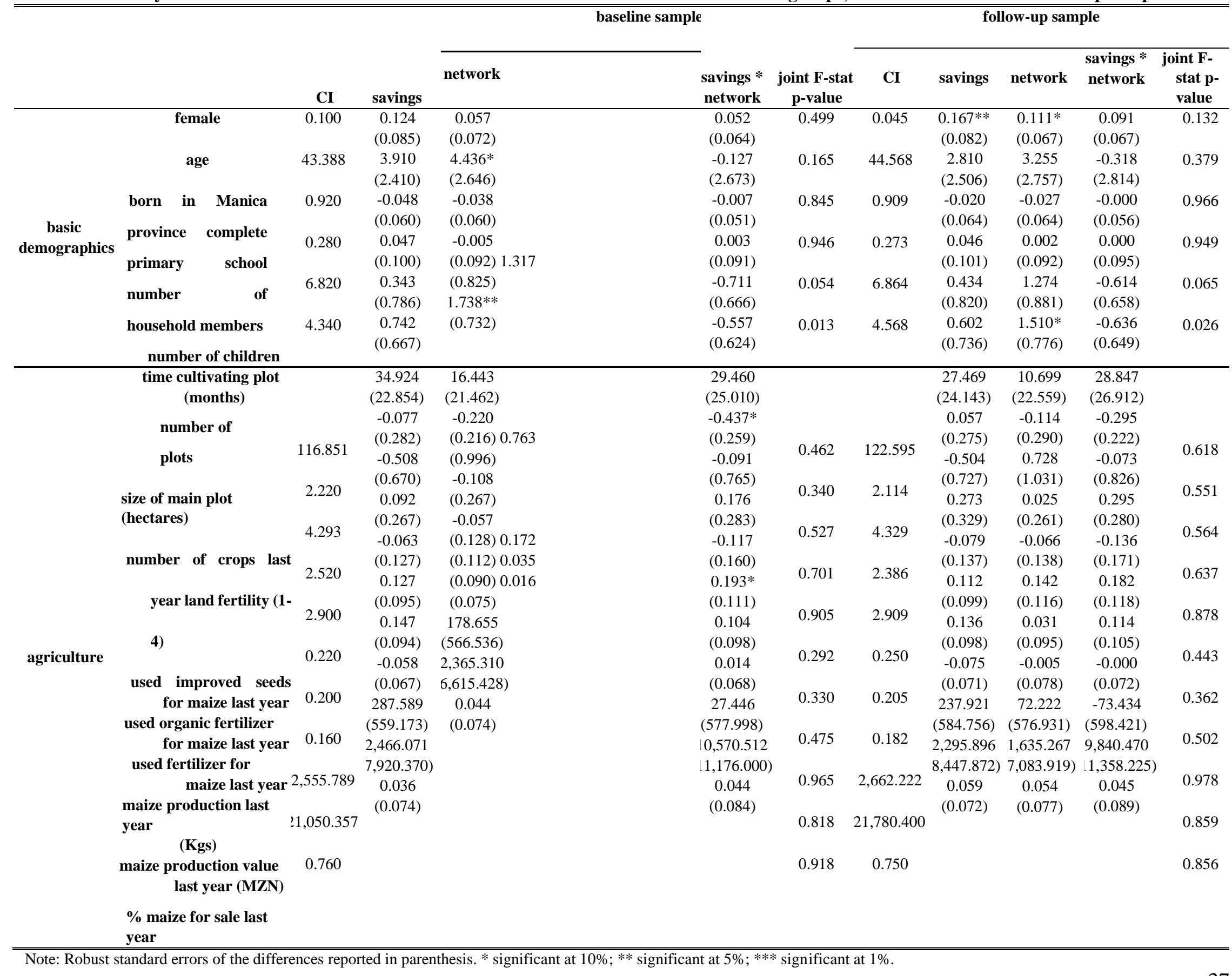


Table 1b: Primary farmers' individual characteristics - differences across treatment and control groups; for both baseline and follow-up samples

\begin{tabular}{|c|c|c|c|c|c|c|c|c|c|c|c|}
\hline & & \multirow[b]{2}{*}{ CI } & \multirow[b]{2}{*}{ savings } & \multicolumn{3}{|c|}{ baseline sample } & \multicolumn{5}{|c|}{ follow-up sample } \\
\hline & & & & network & $\begin{array}{l}\text { savings * } \\
\text { network }\end{array}$ & $\begin{array}{c}\text { joint F-stat } \\
\text { p-value }\end{array}$ & CI & savings & network & $\begin{array}{c}\text { savings } * \\
\text { network }\end{array}$ & $\begin{array}{r}\text { joint } \mathbf{F} \text { - } \\
\text { stat } p- \\
\text { value }\end{array}$ \\
\hline \multirow{6}{*}{ savings } & \multirow{6}{*}{$\begin{array}{l}\text { has bank account } \\
\text { time having a bank } \\
\text { account } \\
\text { (months) } \\
\text { contributes to a saving } \\
\text { group } \\
\text { number of saving groups } \\
\text { time contributing to } \\
\text { saving groups } \\
\text { (months) saving at } \\
\text { home }\end{array}$} & 0.260 & $\begin{array}{c}0.128 \\
(0.094)\end{array}$ & $\begin{array}{c}0.054 \\
(0.071)\end{array}$ & $\begin{array}{c}0.066 \\
(0.077)\end{array}$ & 0.586 & 0.273 & $\begin{array}{c}0.132 \\
(0.104)\end{array}$ & $\begin{array}{c}0.041 \\
(0.077)\end{array}$ & $\begin{array}{c}0.068 \\
(0.085)\end{array}$ & 0.637 \\
\hline & & 79.154 & $\begin{array}{l}-28.321 \\
(29.651)\end{array}$ & $\begin{array}{l}-10.621 \\
(39.861)\end{array}$ & $\begin{array}{l}-14.354 \\
(34.955)\end{array}$ & 0.752 & 82.750 & $\begin{array}{l}-31.917 \\
(31.547)\end{array}$ & $\begin{array}{l}-14.217 \\
(41.830)\end{array}$ & $\begin{array}{l}-17.950 \\
(36.878)\end{array}$ & 0.720 \\
\hline & & 0.140 & $\begin{array}{c}0.044 \\
(0.064)\end{array}$ & $\begin{array}{c}0.036 \\
(0.077)\end{array}$ & $\begin{array}{c}0.012 \\
(0.054)\end{array}$ & 0.921 & 0.136 & $\begin{array}{c}0.034 \\
(0.065)\end{array}$ & $\begin{array}{c}0.040 \\
(0.078)\end{array}$ & $\begin{array}{c}0.023 \\
(0.053)\end{array}$ & 0.947 \\
\hline & & 2.143 & $\begin{array}{l}-0.921 \\
(0.998)\end{array}$ & $\begin{array}{l}-1.032 \\
(1.005)\end{array}$ & $\begin{array}{l}-1.000 \\
(0.869)\end{array}$ & 0.375 & 2.333 & $\begin{array}{l}-1.083 \\
(1.157)\end{array}$ & $\begin{array}{l}-1.222 \\
(1.157)\end{array}$ & $\begin{array}{l}-1.190 \\
(1.023)\end{array}$ & 0.294 \\
\hline & & 48.857 & $\begin{array}{l}-18.302 \\
(19.522)\end{array}$ & $\begin{array}{l}-17.857 \\
(18.080)\end{array}$ & $\begin{array}{c}-21.143 \\
(18.092)\end{array}$ & 0.560 & 50.500 & $\begin{array}{l}-16.875 \\
(22.558)\end{array}$ & $\begin{array}{l}-19.500 \\
(21.041)\end{array}$ & $\begin{array}{l}-22.786 \\
(21.216)\end{array}$ & 0.428 \\
\hline & & 0.820 & $\begin{array}{l}-0.106 \\
(0.087)\end{array}$ & $\begin{array}{l}-0.140 \\
(0.085)\end{array}$ & $\begin{array}{c}0.024 \\
(0.066)\end{array}$ & 0.167 & 0.864 & $\begin{array}{l}-0.119 \\
(0.087)\end{array}$ & $\begin{array}{c}-0.184 * * \\
(0.086)\end{array}$ & $\begin{array}{l}-0.003 \\
(0.068)\end{array}$ & 0.104 \\
\hline
\end{tabular}




\begin{tabular}{|c|c|c|c|c|c|c|c|c|c|c|c|}
\hline \multirow[t]{16}{*}{$\begin{array}{l}\text { expenditure } \\
\text { and assets }\end{array}$} & $\begin{array}{r}\text { total expenditure } \\
(\mathrm{MZN} / \text { month })\end{array}$ & $1,407.204$ & $\begin{array}{c}261.097 \\
(479.768)\end{array}$ & $\begin{array}{c}589.231 \\
(411.227)\end{array}$ & $\begin{array}{l}-109.973 \\
(290.928)\end{array}$ & 0.396 & $1,373.589$ & $\begin{array}{c}329.716 \\
(507.955)\end{array}$ & $\begin{array}{c}622.845 \\
(422.624)\end{array}$ & $\begin{array}{c}-47.557 \\
(316.114)\end{array}$ & 0.403 \\
\hline & owns barn & 0.880 & $\begin{array}{c}0.059 \\
(0.049)\end{array}$ & $\begin{array}{c}0.061 \\
(0.055)\end{array}$ & $\begin{array}{c}0.077 \\
(0.051)\end{array}$ & 0.417 & 0.864 & $\begin{array}{c}0.073 \\
(0.054)\end{array}$ & $\begin{array}{c}0.078 \\
(0.059)\end{array}$ & $\begin{array}{c}0.091 \\
(0.056)\end{array}$ & 0.373 \\
\hline & owns fridge & 0.040 & $\begin{array}{c}0.062 \\
(0.050)\end{array}$ & $\begin{array}{l}-0.020 \\
(0.034)\end{array}$ & $\begin{array}{c}0.003 \\
(0.040)\end{array}$ & 0.372 & 0.045 & $\begin{array}{c}0.040 \\
(0.051)\end{array}$ & $\begin{array}{l}-0.025 \\
(0.038)\end{array}$ & $\begin{array}{l}0.000 \\
(0.044)\end{array}$ & 0.522 \\
\hline & owns sewing & 0.200 & $\begin{array}{l}-0.016 \\
(0.086)\end{array}$ & $\begin{array}{l}-0.020 \\
(0.096) 0.060\end{array}$ & $\begin{array}{l}-0.004 \\
(0.086)\end{array}$ & 0.994 & 0.159 & $\begin{array}{c}0.011 \\
(0.067)\end{array}$ & $\begin{array}{c}0.021 \\
(0.086)\end{array}$ & $\begin{array}{l}0.045 \\
(0.087)\end{array}$ & 0.959 \\
\hline & machine & 0.820 & $\begin{array}{l}-0.004 \\
(0.069)\end{array}$ & $\begin{array}{l}(0.073) \\
-0.109\end{array}$ & $\begin{array}{c}0.071 \\
(0.081)\end{array}$ & 0.695 & 0.841 & $\begin{array}{l}-0.032 \\
(0.075)\end{array}$ & $\begin{array}{c}0.039 \\
(0.075)\end{array}$ & $\begin{array}{c}0.045 \\
(0.083)\end{array}$ & 0.726 \\
\hline & owns radio & 0.429 & $\begin{array}{c}0.020 \\
(0.104)\end{array}$ & $\begin{array}{l}(0.098) \\
-0.140\end{array}$ & $\begin{array}{l}-0.016 \\
(0.106)\end{array}$ & 0.581 & 0.364 & $\begin{array}{c}0.083 \\
(0.099)\end{array}$ & $\begin{array}{l}-0.044 \\
(0.094)\end{array}$ & $\begin{array}{c}0.023 \\
(0.106)\end{array}$ & 0.675 \\
\hline & owns tv & 0.700 & $\begin{array}{l}-0.027 \\
(0.099)\end{array}$ & $\begin{array}{l}(0.093) 0.080 \\
(0.077) 0.020\end{array}$ & $\begin{array}{c}0.061 \\
(0.079)\end{array}$ & 0.183 & 0.682 & $\begin{array}{l}-0.001 \\
(0.102)\end{array}$ & $\begin{array}{l}-0.122 \\
(0.096)\end{array}$ & $\begin{array}{c}0.068 \\
(0.086)\end{array}$ & 0.233 \\
\hline & owns bike & 0.100 & $\begin{array}{l}-0.018 \\
(0.066)\end{array}$ & $\begin{array}{l}(0.051) 0.000 \\
(0.062)\end{array}$ & $\begin{array}{c}0.030 \\
(0.055)\end{array}$ & 0.361 & 0.068 & $\begin{array}{c}0.017 \\
(0.059)\end{array}$ & $\begin{array}{c}0.112 \\
(0.069)\end{array}$ & $\begin{array}{c}0.045 \\
(0.063)\end{array}$ & 0.337 \\
\hline & owns motorcycle & 0.060 & $\begin{array}{c}0.062 \\
(0.060)\end{array}$ & $\begin{array}{l}-0.020 \\
(0.020)\end{array}$ & $\begin{array}{c}0.070 \\
(0.045)\end{array}$ & 0.226 & 0.045 & $\begin{array}{c}0.082 \\
(0.061)\end{array}$ & $\begin{array}{c}0.035 \\
(0.049)\end{array}$ & $\begin{array}{c}0.068 \\
(0.046)\end{array}$ & 0.256 \\
\hline & owns generator & 0.900 & $\begin{array}{c}0.018 \\
(0.060)\end{array}$ & $\begin{array}{l}-0.025 \\
(0.098) 0.020\end{array}$ & $\begin{array}{l}-0.030 \\
(0.065)\end{array}$ & 0.862 & 0.886 & $\begin{array}{c}0.029 \\
(0.064)\end{array}$ & $\begin{array}{c}0.014 \\
(0.065)\end{array}$ & $\begin{array}{c}0.000 \\
(0.066)\end{array}$ & 0.954 \\
\hline & owns animals & 0.020 & $\begin{array}{l}-0.020 \\
(0.020)\end{array}$ & $\begin{array}{l}(0.090) 0.040 \\
(0.100)\end{array}$ & $\begin{array}{c}0.023 \\
(0.036)\end{array}$ & 0.209 & 0.023 & $\begin{array}{l}-0.023 \\
(0.023)\end{array}$ & $\begin{array}{l}-0.023 \\
(0.023)\end{array}$ & $\begin{array}{c}0.023 \\
(0.039)\end{array}$ & 0.207 \\
\hline & owns pump & 0.245 & $\begin{array}{c}0.020 \\
(0.098)\end{array}$ & $\begin{array}{l}-0.039 \\
(0.028)\end{array}$ & $\begin{array}{c}0.038 \\
(0.102)\end{array}$ & 0.929 & 0.273 & $\begin{array}{c}0.004 \\
(0.106)\end{array}$ & $\begin{array}{l}-0.053 \\
(0.102)\end{array}$ & $\begin{array}{c}0.023 \\
(0.110)\end{array}$ & 0.876 \\
\hline & owns improved latrine & 0.280 & $\begin{array}{c}0.026 \\
(0.089)\end{array}$ & & $\begin{array}{c}0.003 \\
(0.080)\end{array}$ & 0.991 & 0.250 & $\begin{array}{c}0.048 \\
(0.090)\end{array}$ & $\begin{array}{c}0.050 \\
(0.096)\end{array}$ & $\begin{array}{c}0.045 \\
(0.081)\end{array}$ & 0.925 \\
\hline & has access to electricity & 0.500 & $\begin{array}{c}0.031 \\
(0.105)\end{array}$ & & $\begin{array}{c}0.043 \\
(0.101)\end{array}$ & 0.969 & 0.523 & $\begin{array}{c}0.009 \\
(0.108)\end{array}$ & $\begin{array}{c}0.017 \\
(0.097)\end{array}$ & $\begin{array}{c}0.045 \\
(0.096)\end{array}$ & 0.973 \\
\hline & has access to piped water & & -0.020 & & -0.022 & & & -0.021 & -0.039 & -0.023 & \\
\hline & $\begin{array}{l}\text { or protected spring } \\
\text { owns mobile phone }\end{array}$ & 1.000 & $(0.020)$ & & $(0.022)$ & 0.275 & 1.000 & $(0.021)$ & $(0.028)$ & $(0.023)$ & 0.274 \\
\hline
\end{tabular}

Table 2: mKesh savings - administrative data dependent variable -----.> average daily savings

first year

(4)

second year

\begin{tabular}{|c|c|c|c|c|c|c|c|}
\hline \multicolumn{3}{|c|}{ first year } & \multirow[b]{2}{*}{ (4) } & \multicolumn{4}{|c|}{ second year } \\
\hline (1) & (2) & (3) & & (5) & (6) & (7) & (8) \\
\hline
\end{tabular}




\begin{tabular}{|c|c|c|c|c|c|c|c|c|c|}
\hline \multirow[t]{3}{*}{ savings $-\beta s$} & \multirow{9}{*}{$\begin{array}{l}\text { coefficient } \\
\text { standard error } \\
\text { q-value } \\
\text { coefficient } \\
\text { standard error } \\
\text { q-value } \\
\text { coefficient } \\
\text { standard error } \\
\text { q-value }\end{array}$} & $0.315 * *$ & $0.318 * *$ & $0.444 * *$ & $0.376^{*}$ & 0.058 & 0.121 & 0.348 & 0.301 \\
\hline & & $(0.147)$ & $(0.150)$ & $(0.204)$ & $(0.207)$ & $(0.230)$ & $(0.229)$ & $(0.281)$ & $(0.314)$ \\
\hline & & {$[0.058]$} & {$[0.055]$} & {$[0.058]$} & {$[0.108]$} & {$[0.795]$} & {$[0.621]$} & {$[0.207]$} & {$[0.342]$} \\
\hline \multirow{6}{*}{ savings*network - $\beta$ SN } & & -0.128 & -0.114 & -0.001 & -0.059 & -0.333 & -0.263 & -0.052 & -0.095 \\
\hline & & $(0.147)$ & $(0.151)$ & $(0.226)$ & $(0.220)$ & $(0.230)$ & $(0.234)$ & $(0.309)$ & $(0.302)$ \\
\hline & & {$[0.391]$} & {$[0.447]$} & {$[0.995]$} & {$[0.911]$} & {$[0.242]$} & {$[0.411]$} & {$[0.975]$} & {$[0.911]$} \\
\hline & & & & -0.263 & -0.115 & & & -0.581 & -0.353 \\
\hline & & & & $(0.297)$ & $(0.299)$ & & & $(0.462)$ & $(0.486)$ \\
\hline & & & & {$[0.400]$} & {$[0.720]$} & & & {$[0.322]$} & {$[0.687]$} \\
\hline \multicolumn{2}{|c|}{ mean dep. variable (control) } & 4.333 & 4.343 & 4.333 & 4.343 & 4.018 & 4.018 & 4.018 & 4.018 \\
\hline \multirow{4}{*}{\multicolumn{2}{|c|}{$\begin{array}{l}\quad \beta s+\beta N=0 \quad \text { F-stat p-value } \beta s \\
+\beta s N=0 \quad \text { F-stat p-value } \beta N+\beta s N= \\
0 \quad \text { F-stat p-value } \beta s+\beta N+\beta s N=0 \text { F- } \\
\text { stat p-value }\end{array}$}} & 0.324 & 0.302 & & & 0.409 & 0.653 & & \\
\hline & & & & 0.400 & 0.231 & & & 0.524 & 0.882 \\
\hline & & & & 0.162 & 0.397 & & & 0.067 & 0.231 \\
\hline & & & & 0.339 & 0.309 & & & 0.393 & 0.646 \\
\hline \multirow{2}{*}{\multicolumn{2}{|c|}{$\begin{array}{c}\text { r-squared adjusted } \\
\text { number of observations }\end{array}$}} & 0.037 & 0.059 & 0.035 & 0.052 & -0.004 & 0.028 & 0.000 & 0.024 \\
\hline & & 146 & 142 & 146 & 142 & 144 & 140 & 144 & 140 \\
\hline \multicolumn{2}{|c|}{ controls } & no & yes & no & yes & no & yes & no & yes \\
\hline
\end{tabular}

Note: All regressions are OLS. Dependent variable is log savings. Data was made available by the mKesh operator for the period between June 2013 and June 2015. All regressions include district fixed effects. Controls are gender, age, whether the individual was born in Manica province, whether the individual has completed primary school, number of household members, and number of children. Robust standard errors reported in parenthesis. Q-values adjusted for multiple hypothesis testing following Romano and Wolf (2016) are presented in brackets. * significant at 10\%; ** significant at $5 \%$; *** significant at $1 \%$.

Table 3: Savings - survey

dependent variable ----..>

overall savings (aggregate)

(1) (2) (3) (4)




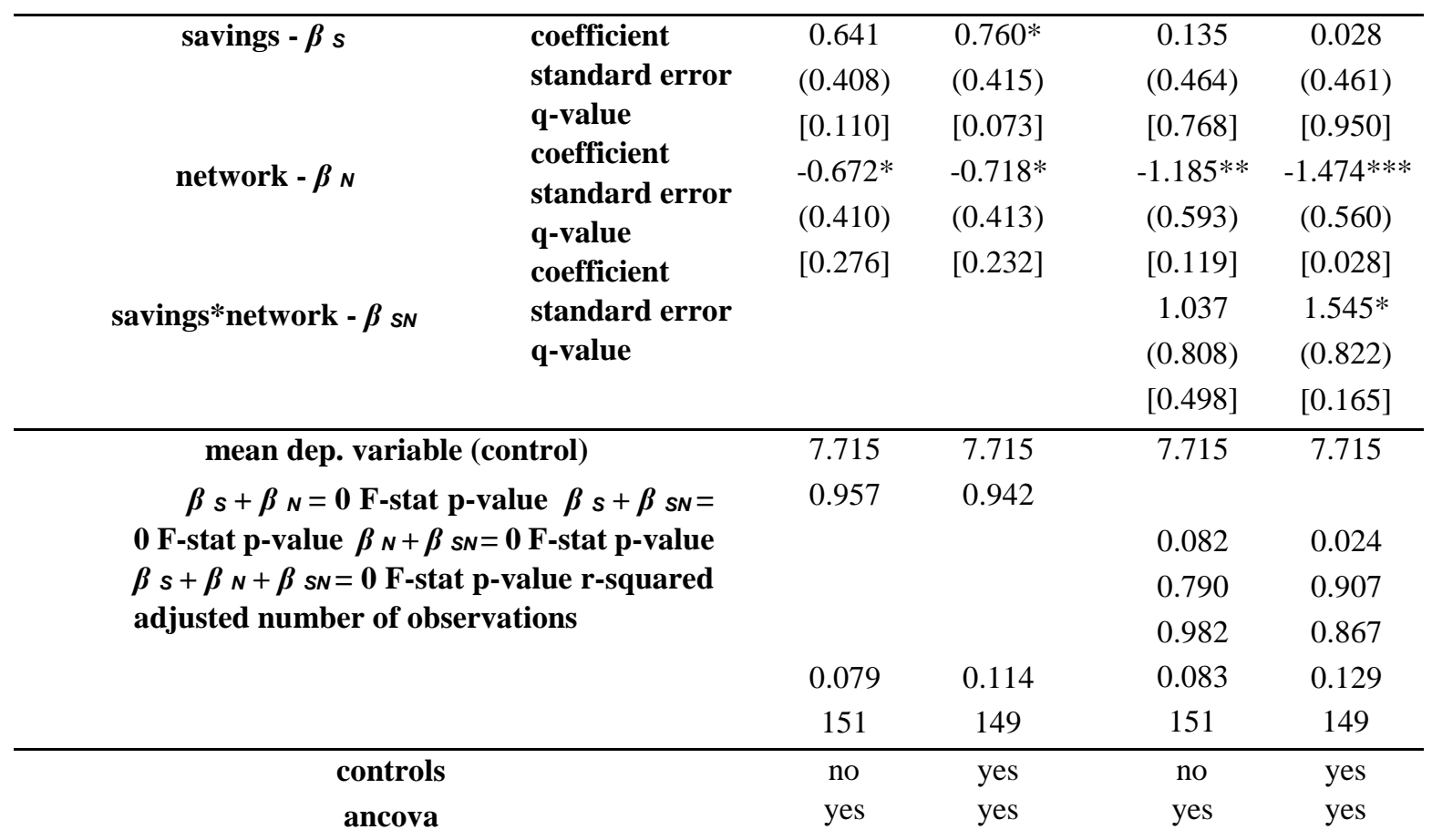

Note: All regressions are Ancova. Dependent variable is the log value of aggregate savings, based on survey questions asked in both the baseline and endline surveys. All regressions include district fixed effects.

Controls are gender, age, whether the individual was born in Manica province, whether the individual has completed primary school, number of household members, and number of children. Robust standard errors reported in parenthesis. Q-values adjusted for multiple hypothesis testing following Romano and Wolf (2016)

are presented in brackets. * significant at 10\%; ** significant at 5\%; *** significant at $1 \%$.

Table 4a: Agricultural inputs

\begin{tabular}{|c|c|c|c|c|c|c|c|c|c|c|c|c|c|c|c|}
\hline \multicolumn{4}{|c|}{ dependent variable ------> } & \multicolumn{2}{|l|}{ used fertilizer (binary) } & \multicolumn{5}{|c|}{ kgs fertilizer used } & \multicolumn{5}{|c|}{ knowledge about using fertilizer } \\
\hline & & (1) & (2) & (3) & (4) & (5) & (6) & & & (7) & (8) & (9) & (10) & (11) & (12) \\
\hline \multirow[t]{3}{*}{ savings $-\beta_{S}$} & coefficient & $0.361 * * *$ & $0.338 * * *$ & $0.307 * * *$ & $0.280 * * *$ & $13.750 * *$ & $14.628 * *$ & & & 13.176 & 12.020 & $0.132 * *$ & $0.137 *$ & $* 0.154 *$ & $0.175^{* *}$ \\
\hline & standard & $(0.060)$ & $(0.063)$ & $(0.085)$ & $(0.090)$ & $(6.992)$ & $(7.431)$ & & & $(11.602)$ & $(10.982)$ & $(0.056)$ & $(0.054)$ & $(0.080)$ & $(0.078)$ \\
\hline & error q- & {$[0.000]$} & {$[0.000]$} & {$[0.001]$} & {$[0.002]$} & [0.049] & [0.049] & & & {$[0.263]$} & [0.301] & [0.033] & {$[0.019]$} & ] [0.099] & [0.048] \\
\hline \multirow[t]{3}{*}{ network - $\beta_{N}$} & coefficient & -0.084 & -0.074 & $-0.136^{* *}$ & $-0.129 *$ & -5.865 & -7.410 & & & -6.421 & -9.916 & $-0.105^{*}$ & -0.096 & * -0.084 & -0.059 \\
\hline & standard & $(0.060)$ & $(0.061)$ & $(0.066)$ & $(0.072)$ & $(6.952)$ & (7.677) & & & $(5.595)$ & $(6.306)$ & $(0.055)$ & $(0.055)$ & $(0.076)$ & $(0.075)$ \\
\hline & error q- & [0.305] & [0.398] & [0.119] & {$[0.136]$} & [0.383] & [0.309] & & & {$[0.424]$} & [0.211] & {$[0.129]$} & {$[0.166]$} & [0.424] & [0.433] \\
\hline \multicolumn{2}{|c|}{ savings*network value } & & & 0.106 & 0.113 & & & & & 1.135 & 5.152 & & & -0.044 & -0.075 \\
\hline \multirow[t]{3}{*}{$-\beta S N$} & coefficient & & & $(0.123)$ & $(0.130)$ & & & & & & & & & $(0.112)$ & $(0.114)$ \\
\hline & standard & & & {$[0.617]$} & {$[0.630]$} & & & [0.942] & [0.699] & & & & & [0.911] & {$[0.742]$} \\
\hline & value & 0.227 & 0.227 & & & 9.857 & & 9.857 & 9.857 & & & & & & \\
\hline
\end{tabular}




\begin{tabular}{|c|c|c|c|c|c|c|c|c|c|c|c|c|}
\hline $\begin{array}{l}\text { mean dep. variable } \\
\text { (control) }\end{array}$ & 0.003 & 0.007 & 0.227 & 0.227 & 0.367 & 0.432 & $(14.461)$ & (13.305) & $\begin{array}{l}0.545 \\
0.726\end{array}$ & $\begin{array}{l}0.545 \\
0.600\end{array}$ & 0.545 & 0.545 \\
\hline $\boldsymbol{\beta}_{S}+\boldsymbol{\beta}_{N}=0$ F-stat & & & 0.000 & 0.000 & & & & & & & 0.160 & 0.210 \\
\hline p-value $\beta s+\beta s_{N}=0$ & & & 0.772 & 0.984 & & & & & & & 0.124 & 0.106 \\
\hline F-stat p-value $\beta_{N}+\beta$ & 0.245 & 0.238 & 0.003 & 0.010 & 0.058 & 0.054 & 0.087 & 0.056 & & & 0.728 & 0.605 \\
\hline$S N=0$ F-stat p-value $\beta$ & 186 & 182 & 0.244 & 0.237 & 177 & 174 & 0.689 & 0.716 & 0.031 & 0.089 & 0.026 & 0.086 \\
\hline $\begin{array}{lr}s+\beta_{N}+\beta \\
\text { p-value }\end{array}$ & & & 186 & 182 & & & 0.369 & 0.433 & 184 & 180 & 184 & 180 \\
\hline adjusted number of & & & & & & & 0.053 & 0.049 & & & & \\
\hline observations & & & & & & & 177 & 174 & & & & \\
\hline controls & no & yes & no & yes & no & yes & no & yes & no & yes & no & yes \\
\hline ancova & yes & yes & yes & yes & no & no & no & no & no & no & no & no \\
\hline
\end{tabular}

Note: All regressions are ANCOVA or OLS. All dependent variables are based on survey questions asked in the endline survey or both the basline and endline surveys, depending on data availability. All regressions include district fixed effects. Controls are gender, age, whether the individual was born in Manica province, whether the individual has completed primary school, number of household members,

and number of children. Robust standard errors reported in parenthesis. Q-values adjusted for multiple hypothesis testing following Romano and Wolf (2016) are presented in brackets. * significant at $10 \%$; ** significant at $5 \%$; *** significant at $1 \%$.

\section{Table 4b: Agricultural inputs}

\begin{tabular}{|c|c|c|c|c|c|c|c|c|c|c|c|c|c|}
\hline \multicolumn{2}{|c|}{ dependent variable --.--.> } & \multicolumn{4}{|c|}{ improved seeds usage } & \multicolumn{4}{|c|}{ number of workers employed in farm } & \multicolumn{4}{|c|}{ irrigation pumps ownership } \\
\hline \multirow[b]{2}{*}{$\beta s$} & \multirow{9}{*}{$\begin{array}{l}\text { standard error } \\
\text { q-value } \\
\text { coefficient } \\
\text { standard error } \\
\text { q-value } \\
\text { coefficient } \\
\text { standard error }\end{array}$} & (1) & (2) & (3) & (4) & & & & & & & & \\
\hline & & $(0.071)$ & $(0.070)$ & $(0.102)$ & $(0.106)$ & $(0.740)$ & $(0.753)$ & $(1.139)$ & $(1.099)$ & $(0.019)$ & $(0.022)$ & $(0.030)$ & $(0.033)$ \\
\hline \multirow{7}{*}{ savings*network - $\beta S_{S N}$} & & [0.491] & [0.391] & [0.967] & {$[0.868]$} & {$[0.496]$} & {$[0.391]$} & {$[0.967]$} & {$[0.868]$} & {$[0.252]$} & {$[0.245]$} & [0.445] & [0.439] \\
\hline & & -0.062 & -0.026 & -0.143 & -0.079 & 0.501 & 0.346 & 0.234 & 0.006 & -0.009 & -0.010 & -0.003 & -0.005 \\
\hline & & $(0.070)$ & $(0.069)$ & $(0.101)$ & $(0.106)$ & $(0.719)$ & $(0.702)$ & $(1.100)$ & $(0.999)$ & (0.019) & $(0.019)$ & $(0.004)$ & $(0.006)$ \\
\hline & & {$[0.740]$} & [0.935] & {$[0.360]$} & {$[0.778]$} & {$[0.740]$} & [0.935] & {$[0.826]$} & [0.992] & {$[0.740]$} & {$[0.935]$} & {$[0.554]$} & {$[0.778]$} \\
\hline & & & & 0.168 & 0.108 & & & 0.549 & 0.702 & & & -0.013 & -0.011 \\
\hline & & & & $(0.141)$ & $(0.146)$ & & & (1.563) & (1.435) & & & $(0.039)$ & $(0.042)$ \\
\hline & & & & & & (5) & (6) & (7) & (8) & (9) & (10) & (11) & (12) \\
\hline & & & & & & & 0.866 & 0.254 & 0.507 & $0.034^{*}$ & $0.039^{*}$ & 0.040 & 0.045 \\
\hline
\end{tabular}

\begin{tabular}{|c|c|c|c|}
\hline mean dep. variable (control) & 0.523 & 0.523 & 0.523 \\
\hline$\beta s+\beta_{N}=0$ F-stat p-value & 0.885 & 0.567 & \\
\hline $\boldsymbol{\beta} s+\boldsymbol{\beta} s N=0$ F-stat p-value $\boldsymbol{\beta}$ & & & 0.102 \\
\hline$N+\beta s N=0$ F-stat p-value $\beta s$ & & & 0.801 \\
\hline$+\beta_{N}+\beta S_{N}=0$ F-stat p-value & & & 0.879 \\
\hline r-squared adjusted number & 0.105 & 0.157 & 0.107 \\
\hline & 185 & 181 & 185 \\
\hline
\end{tabular}

\begin{tabular}{ccccccccc}
\hline 7.386 & 7.386 & 0.429 & 0.221 & & 0.000 & 0.000 & 0.000 & 0.000 \\
0.377 & 0.306 & 0.445 & 0.485 & & 0.297 & 0.245 & & \\
& & 0.376 & 0.306 & & & 0.281 & 0.230 \\
& & 0.197 & 0.214 & & & 0.685 & 0.695 \\
& & 186 & 182 & & & 0.306 & 0.253 \\
0.201 & 0.218182 & no & yes & 0.005 & 0.003 & 0.000 & -0.002 \\
& & yes & yes & & 183 & 179 & 183 & 179 \\
\hline \hline
\end{tabular}




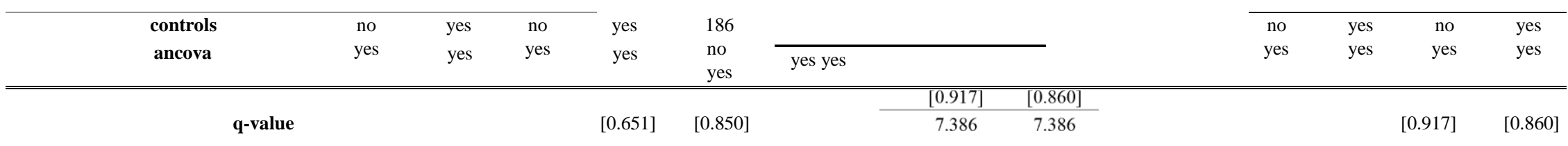

Note: All regressions are ANCOVA. All dependent variables are based on survey questions asked in the baseline and endline surveys, depending on data availability. All regressions include district fixed effects. Controls are gender, age, whether the individual was born in Manica province, whether the individual has completed primary school, number of household members, and number of children. Robust

standard errors reported in parenthesis. Q-values adjusted for multiple hypothesis testing following Romano and Wolf (2016) are presented in brackets. * significant at $10 \%$; ** significant at $5 \%$; *** significant at $1 \%$.

Table 5: Household expenditures

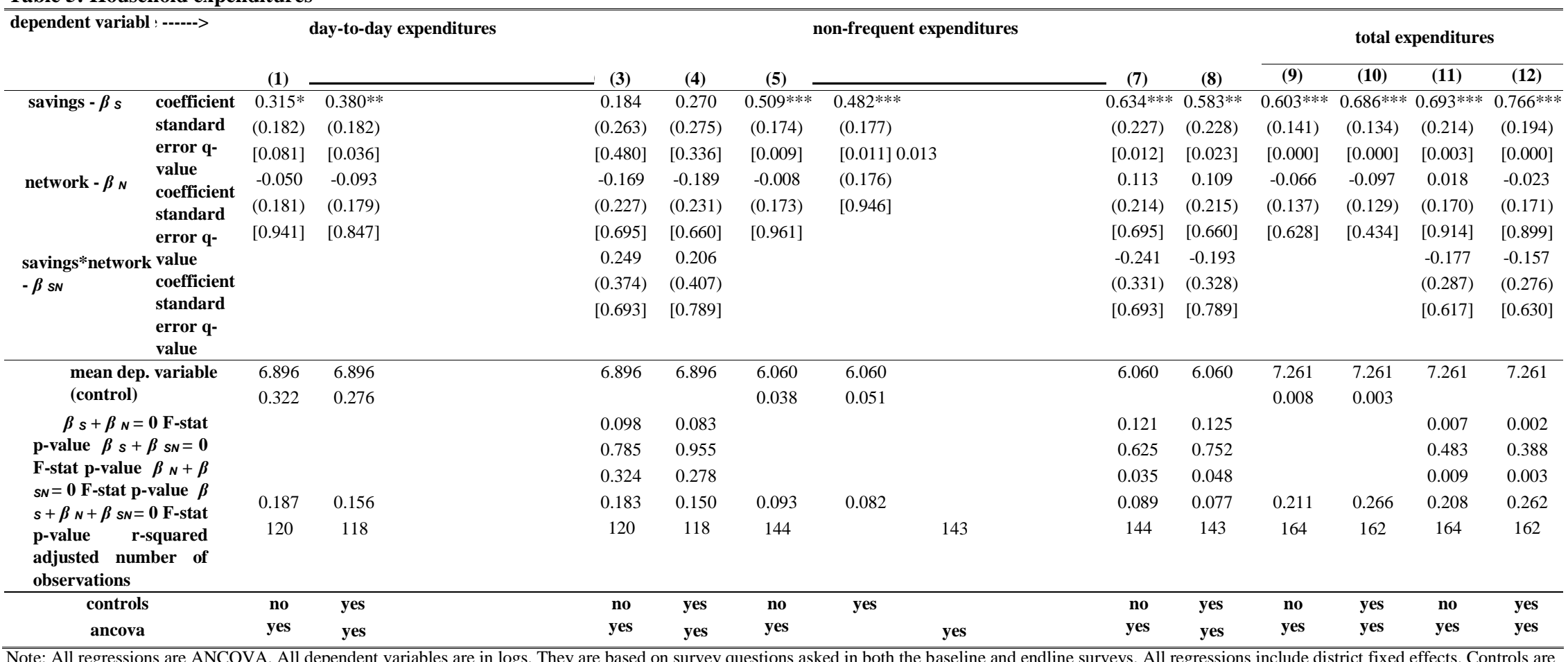

Note: All regressions are ANCOVA. All dependent variables are in logs. They are based on survey questions asked in both the baseline and endline surveys. All regressions include district fixed effects. Controls are parenthesis. Q-values adjusted for multiple hypothesis testing following Romano and Wolf (2016) are presented in brackets. * significant at 10\%; ** significant at 5\%; *** significant at 1\%.* significant at 10\%; **
significant at 5\%; *** significant at 1\%. significant at $5 \%$; *** significant at $1 \%$. 
